\title{
D3 Receptors Regulate Excitability in a Unique Class of Prefrontal Pyramidal Cells
}

\author{
Rebecca L. Clarkson, ${ }^{1,2}$ Alayna T. Liptak, ${ }^{1}$ Steven M. Gee, ${ }^{1,2}$ ○Vikaas S. Sohal, ${ }^{1,4}$ and ${ }^{\odot}$ Kevin J. Bender ${ }^{1,3}$ \\ ${ }^{1}$ Weill Institute for Neuroscience and Center for Integrative Neuroscience, ${ }^{2}$ Graduate Program in Neuroscience, ${ }^{3}$ Department of Neurology, and \\ ${ }^{4}$ Department of Psychiatry, University of California, San Francisco, California 94158
}

The D3 dopamine receptor, a member of the $\mathrm{G}_{\mathrm{i}}$-coupled $\mathrm{D} 2$ family of dopamine receptors, is expressed throughout limbic circuits affected in neuropsychiatric disorders, including prefrontal cortex (PFC). These receptors are important for prefrontal executive function because pharmacological and genetic manipulations that affect prefrontal D3 receptors alter anxiety, social interaction, and reversal learning. However, the mechanisms by which D3 receptors regulate prefrontal circuits and whether D3 receptors regulate specific prefrontal subnetworks remains unknown. Here, we combine dopamine receptor reporter lines, anatomical tracing techniques, and electrophysiology to show that D3 receptor expression defines a novel subclass of layer 5 glutamatergic pyramidal cell in mouse PFC (either sex). D3-receptor-expressing pyramidal neurons are electrophysiologically and anatomically separable from neighboring neurons expressing D1 or D2 receptors based on their dendritic morphology and subthreshold and suprathreshold intrinsic excitability. D3-receptorexpressing neurons send axonal projections to intratelencephalic (IT) targets, including contralateral cortex, nucleus accumbens, and basolateral amygdala. Within these neurons, D3 receptor activation was found to regulate low-voltage-activated $\mathrm{Ca}_{\mathrm{V}} 3.2$ calcium channels localized to the axon initial segment, which suppressed action potential (AP) excitability, particularly when APs occurred at high frequency. Therefore, these data indicate that D3 receptors regulate the excitability of a unique, IT prefrontal cell population, thereby defining novel circuitry and cellular actions for D3 receptors in PFC.

Key words: axon initial segment; calcium channel; dopamine; electrophysiology; prefrontal

Significance Statement

The D3 dopamine receptor, a member of the $\mathrm{G}_{\mathrm{i}}$-coupled D2 family of dopamine receptors, are expressed throughout limbic circuits, including prefrontal cortex (PFC). They are of broad interest as a site for therapeutic intervention in serious mental illness, yet we know very little about their distribution or function within PFC. Here, we show that D3 receptors define a unique population of glutamatergic principal cells in mouse PFC that largely lack expression of D1 or D2 receptors. Within these cells, we find that $\mathrm{D} 3$ receptors regulate the ability to generate high-frequency action potential bursts through mechanisms not supported by other dopamine receptors. These results define unique circuitry and cellular actions for D3 receptors in regulating PFC networks.

\section{Introduction}

The $G_{i / o}$-coupled D2 family of dopamine receptors is important for normal prefrontal function and dysfunction of these recep-

Received Jan. 20, 2017; revised April 13, 2017; accepted April 18, 2017.

Author contributions: R.L.C., V.S.S., and K.J.B. designed research; R.L.C., A.T.L., S.H.G., and K.J.B. performed research; R.L.C., A.T.L., and K.J.B. analyzed data; R.L.C. and K.J.B. wrote the paper.

This work was supported by the National Science Foundation (Graduate Research Fellowship 1144247 to R.L.C.) and the National Institutes of Health (Grants DC011080, DA035913, and MH112729 to K.J.B. and Grant MH100292 to V.S.S.). TTA-P2 was generously provided by Merck. We thank Howard Fields, Michael Roberts, Sidney Kuo, Gregory Hjelmstad, Patrick Sheets, and members of the Bender laboratory for discussions and comments on this work and Madeline Ferwerda, Jiggy Athilingam, and Caroline Keeshen for sharing their genotyping expertise.

The authors declare no competing financial interests.

Correspondence should be addressed to Kevin J. Bender, UCSF Sandler Neurosciences Center, Box 0444, 675 Nelson Rising Lane, Room 514A, San Francisco, CA 94158. E-mail: kevin.bender@ucsf.edu. tors underlies multiple forms of serious mental illness (Minzer et al., 2004; Laruelle, 2014). Although considerable attention has been paid to the function of D2 receptors (D2Rs) themselves, the cellular mechanisms by which other D2-family receptors, including $\mathrm{D} 3$ receptors (D3Rs), regulate prefrontal cortex (PFC) neurons remain unclear. D3Rs appear to play an important role in normal PFC function and potentially in mental illness treatment because currently prescribed antipsychotics have equal affinity for D3R and D2R (Joyce and Millan, 2005; Gross et al., 2013). Moreover, alterations in medial PFC (mPFC)-dependent learning tasks are evident in both D3R knock-out animals and with

DOI:10.1523/JNEUROSCI.0310-17.2017

Copyright $\odot 2017$ the authors $\quad 0270-6474 / 17 / 375846-15 \$ 15.00 / 0$ 
pharmacological manipulation of prefrontal D3Rs (Glickstein et al., 2002, 2005; Millan et al., 2010; Nakajima et al., 2013). Therefore, determining the cellular substrates of prefrontal D3R modulation and the resulting effects on neuronal computation is essential for our understanding of mPFC function in health and disease.

Major advances in understanding striatal circuitry were made after the discovery that D1 receptors (D1Rs) and D2Rs map onto medium spiny neurons that comprise the direct and indirect pathway (Gerfen and Surmeier, 2011). In prefrontal circuits, parallel observations are beginning to emerge, as recent work indicates that D1R and D2R regulate thin- and thick-tufted layer 5 (L5) pyramidal cells, respectively (Gee et al., 2012; Seong and Carter, 2012). These pyramidal cell subclasses are part of distinct circuits: thin-tufted pyramidal cells are intratelencephalic (IT), with projections to contralateral cortex; thick-tufted pyramidal cells are pyramidal tract (PT), with projections to thalamus and pons, but not contralateral cortex (Dembrow et al., 2010; Gee et al., 2012). Given that D1Rs and D2Rs are expressed in largely separate L5 pyramidal cell subclasses that have unique electrophysiological and morphological features (Gee et al., 2012; Seong and Carter, 2012), we hypothesized that D3R expression may be restricted to one of these subclasses or to an additional subclass with its own electrophysiological signature. However, how D3Rs are incorporated in and regulate the activity of prefrontal neurons is not clear.

Here, we used dopamine receptor reporter lines, anatomical tracing techniques, and electrophysiology to understand D3dependent regulation in PFC. In contrast to striatum, which contains only two principle classes of medium spiny neuron, we found that D3R expression defines an additional class of L5 pyramidal cells that largely lack D1R or D2R coexpression. Despite $\mathrm{D} 3 \mathrm{R}$ and $\mathrm{D} 1 \mathrm{R}$ belonging to different dopamine receptor families (D2-like, D1-like), L5 D3R-expressing neurons were more comparable to D1R-expressing cells in their synaptic connectivity, with projections to IT areas, including contralateral cortex. D3R-expressing neurons could be distinguished from D1R- or D2R-expressing neurons by dendritic morphology and intrinsic electrophysiological properties, and by the manner in which dopamine regulated neuronal function. In these neurons, D3Rs selectively regulated the dynamics of voltage-gated calcium channels localized to the site of action potential (AP) initiation in the axon initial segment (AIS), which in turn led to a marked suppression in the generation of high-frequency AP bursts. Similar signaling mechanisms were not observed in neighboring D1R- or $\mathrm{D} 2 \mathrm{R}$-expressing cells, indicating that $\mathrm{D} 3 \mathrm{R}$ s have a unique role in the regulation of pyramidal cell excitability. Therefore, these results reveal a specific role for D3R signaling in prefrontal networks and highlight new signaling pathways and circuitries that may contribute to antipsychotic efficacy in PFC.

\section{Materials and Methods}

Electrophysiological recordings. All procedures were in accordance with University of California, San Francisco Institutional Animal Care and Use Committee guidelines. After anesthesia, para-coronal slices in plane with mPFC L5 apical dendrites $(225-300 \mu \mathrm{m})$ were made from postnatal day (P)25-P60 C57 or transgenic mice of either sex. Transgenic animals (TH-Cre::Ai32; D1-tdTomato/D3-cre; D2-Cre; D3-Cre; D3-Cre::Ai14; D1-tdTomato/D2-eGFP; and $\mathrm{D}^{-1-}$, all on C57 background) were genotyped by PCR. Transgenic mice lines had the following research resource identifiers: TH-cre, IMSR_JAX:008601; D1-tdTomato, IMSR_ JAX:016204; D2-Cre, MMRRC_032108-UCD; D2-eGFP, MMRRC_000230UNC; D3-Cre (KJ302), MMRRC_034696-UCD; D3 ${ }^{-1-}$, MGI:4839942. No differences were observed across mouse lines and results were pooled.
Cutting solution contained the following (in $\mathrm{mm}$ ): $87 \mathrm{NaCl}, 25 \mathrm{NaHCO}_{3}$, 25 glucose, 75 sucrose, $2.5 \mathrm{KCl}, 1.25 \mathrm{NaH}_{2} \mathrm{PO}_{4}, 0.5 \mathrm{CaCl}_{2}$ and $7 \mathrm{MgCl}_{2}$ bubbled with $5 \% \mathrm{CO}_{2} / 95 \% \mathrm{O}_{2} ; 4^{\circ} \mathrm{C}$. After cutting, slices were either incubated in the same solution or in the recording solution (see below) for 30 min at $33^{\circ} \mathrm{C}$ and then at room temperature until recording. Recording solution contained the following (in mM): $125 \mathrm{NaCl}, 2.5 \mathrm{KCl}, 2 \mathrm{CaCl}_{2}, 1$ $\mathrm{MgCl}_{2}, 25 \mathrm{NaHCO}_{3}, 1.25 \mathrm{NaH}_{2} \mathrm{PO}_{4}, 25$ glucose bubbled with $5 \% \mathrm{CO}_{2} /$ $95 \% \mathrm{O}_{2}$ at $32-34^{\circ} \mathrm{C}$.

Pyramidal cells were visualized with Dodt or differential interference contrast optics; L5 was targeted as the less dense region below L2/3, visualized as the thin band of densely packed somata. For current-clamp recordings, patch electrodes (Schott 8250 glass, 3-4 M $\Omega$ tip resistance, $<15 \mathrm{M} \Omega$ series resistance) were filled with a solution containing the following (in mM): $113 \mathrm{~K}$-gluconate, $9 \mathrm{HEPES}, 4.5 \mathrm{MgCl}_{2}, 0.1 \mathrm{EGTA}, 14$ Tris $_{2}$-phosphocreatine, $4 \mathrm{Na}_{2}$-ATP, 0.3 tris-GTP at $\sim 290 \mathrm{mOsm}, \mathrm{pH}$ 7.2-7.25. For Ca imaging, EGTA was replaced with $250 \mu \mathrm{m}$ Fluo-5F and $20 \mu \mathrm{M}$ Alexa Fluor 594. Electrophysiological data were recorded at 20-50 $\mathrm{kHz}$ and filtered at $10 \mathrm{kHz}$ using a Multiclamp 700A or 700B amplifier (Molecular Devices) and acquired with custom routines in Igor Pro (Wavemetrics). For assessing AIS Ca modulation, $V_{\mathrm{m}}$ was held at -80 $\mathrm{mV}$ (corrected for a $12 \mathrm{mV}$ measured junction potential) and cells were excluded if $R_{\text {in }}$ changed by $> \pm 15 \%$.

Targeted Ni iontophoresis was done as described previously (Bender et al., 2012) using a Dagan ION-100 (50-100 nA ejection current, $-20 \mathrm{nA}$ retention current). Phosphates were omitted from recording solutions to avoid $\mathrm{Ni}_{3}\left(\mathrm{PO}_{4}\right)_{2}$ formation at the electrode tip. Ni application temporally overlapped somatic current or conductance injection. Excitatory postsynaptic conductances were injected in dynamic clamp using an ITC-18 interface as pure AMPA-mediated conductances $(0 \mathrm{mV}$ reversal potential, Poisson distributed, $\tau_{\text {rise }}=0.4 \mathrm{~ms}, \tau_{\text {decay }}=4 \mathrm{~ms}$, amplitude scaled within each experiment to evoke spikes).

For endogenous dopaminergic fiber stimulation, channelrhodopsin-2 (ChR2) was activated by full-field $470 \mathrm{~nm}$ light ( $2 \mathrm{~mW}$ at the focal point) using a purpose-built light-emitting diode assembly. Stimuli were delivered in a burst of 10 light pulses at $40 \mathrm{~Hz}$ ( $5 \mathrm{~ms}$ per stimulus). These bursts were repeated $10 \times$ every $60 \mathrm{~s}$. Because ChR2 is expressed in both dopaminergic and noradrenergic cells in TH-Cre::Ai32 animals, noradrenergic receptors were blocked with $10 \mu \mathrm{M}$ yohimbine hydrochloride, $1 \mu \mathrm{M}$ alfuzosis hydrochloride, and $10 \mu \mathrm{M}$ ICI 118,551 hydrochloride.

For voltage clamp of Ca currents, experiments were performed in D1-tdTomato/D2-eGFP or D3-Cre::Ai14 mice, allowing fluorescent targeting of pyramidal cell subclasses. Internal solution contained the following (in mM): $110 \mathrm{CsMeSO}_{3}, 40 \mathrm{HEPES}, 1 \mathrm{KCl}, 4 \mathrm{NaCl}, 4 \mathrm{Mg}$-ATP, 10 Na-phosphocreatine, $0.4 \mathrm{Na}_{2}$-GTP, 0.5 Fluo-5F, and 0.02 Alexa Fluor594 at $\sim 290 \mathrm{mOsm}, \mathrm{pH} 7.22$, voltages adjusted for $11 \mathrm{mV}$ junction potential. Experiments were performed in the presence of $500 \mathrm{~nm}$ tetrodotoxin (TTX), $1 \mathrm{~mm} \mathrm{CsCl}, 10 \mu \mathrm{M}$ SR95531, and $10 \mu \mathrm{M}$ NBQX. T-type $\mathrm{Ca}^{2+}$ currents were activated with $100 \mathrm{~ms}$ voltage steps from -100 to $-50 \mathrm{mV}$. For T-type current measurements, leak currents were subtracted using a $\mathrm{P} / 4$ protocol with $-12.5 \mathrm{mV}$ steps from $-80 \mathrm{mV}$.

Electrophysiological analysis for classification. Electrophysiological characteristics (sag/rebound, AP spike train/waveform) were determined from voltage responses to hyperpolarizing $(-400 \mathrm{pA}, 120 \mathrm{~ms})$ and depolarizing (300 ms, 20-300 pA) square current pulses from a holding potential of $-80 \mathrm{mV}$.

Latency to peak sag was calculated as the time from current pulse onset to the negative peak of the voltage. Sag amplitude was defined as the amplitude of a one-term exponential model fit to the voltage between peak sag onset and the end of the current pulse. Latency to peak rebound was defined as the time from the end of the current pulse to the maximum voltage within $100 \mathrm{~ms}$ of pulse offset. Rebound time constant was defined as the duration after current offset for a voltage increase from $20-80 \%$ of the difference between the peak rebound voltage and the voltage at current offset.

AP threshold was defined as the voltage at which the first derivative of the membrane potential exceeded $15 \mathrm{~V} / \mathrm{s}$ (McCormick et al., 2007). AP amplitude was calculated as the difference between the maximum AP membrane potential and AP threshold. The rate of the AP rising, rate of AP falling, and spike width were all calculated at $20 \%$ of AP amplitude for 
the given amplitude, with rates calculated as the first derivative of membrane potential with respect to time. Afterhyperpolarization (AHP) potential of APs in a spike train was defined as the minimum voltage between APs. A doublet index was calculated as the ratio of the second to first interspike interval.

Linear discriminant analysis (LDA): model development and application. Five features were chosen for LDA: sag amplitude, rebound time constant, the log of the doublet index, rate of AP rising phase for the last $\mathrm{AP}$ in the spike train, and difference in AP threshold between first and last AP. None of these variables was tightly correlated (defined as $r^{2}>0.5$ and $p<0.05$ ) or strongly non-normal (Lilliefors test, $p<0.001$ ). Variables were standardized by rescaling to have a mean of zero and an SD of one.

Twelve classifiers were created using the machine learning toolbox (MATLAB), depending on Ca buffer in the recording pipette (EGTA or Fluo-5F) and number of APs evoked in $300 \mathrm{~ms}$ (3-8 APs). Repeated holdout cross-validation $(2000 \times)$ validated the discriminant functions. For each iteration, data were randomly partitioned into a training set $(90 \%)$ and a testing set $(10 \%)$, with the linear discriminant determined by the training set then applied to the testing set. Prediction accuracy was averaged across rounds, defined as the percentage of cells correctly identified in the testing set. Prediction accuracy was increased by defining an "exclusion zone," determined by the Gaussian fit of the D1+ and D3+ cell class' Euclidean distances from the discriminant hyperplane (i.e., decision boundary). The exclusion zone was defined such that only nonlabeled cells with distances from the boundary outside of the 95th percentile of the other cell class' distribution were classified as "Type 1" or "Type 3" (see Fig. 2D). The final set of classifiers was applied to all nongenetically identified cells to predict D1R or D3R expression. Each cell was tested on all relevant classifiers, depending on Ca buffer and AP spike number. Cells were included in subsequent analysis if they were classified outside the exclusion zone and did not have their designation switch from Type 1 to Type 3 (or vice versa) between classifiers.

Laminar distribution and orthograde/retrograde tracing. Before all viral injections, mice were anesthetized and positioned in a stereotaxic frame. For laminar expression experiments, P28-P35 D1-tdTomato/D3-cre or D2-cre mice were injected bilaterally with large volumes (750-1000 nl) of either AAV-EF $1 \alpha$-DIO-EYFP or AAV-EF1 $\alpha$-DIO-mCherry in the $\mathrm{mPFC}$ (stereotaxic coordinates $[\mathrm{mm}]$ : anteriorposterior $[\mathrm{AP}],+1.7$, mediolateral $[\mathrm{ML}]+/-0.3$; dorsoventral $[\mathrm{DV}]:-2.75)$. Four to 5 weeks after injection, animals were fixed with $4 \%$ paraformaldehyde in PBS via transcardial perfusion. After full brain fixation $(4 \mathrm{~h}), 50 \mu \mathrm{m}$ coronal sections of the $\mathrm{MPFC}$ were made in PBS using a vibratome.

In preparation for anti-RFP immunohistochemistry, free-floating coronal sections were rinsed with PBS $(3 \times)$ and blocked $1 \mathrm{~h}$ at room temperature (BlockAid blocking solution). Sections were incubated overnight at $4^{\circ} \mathrm{C}$ in primary antibody (mouse anti-RFP, 1:500) in PBS-T (PBS with $0.1 \%$ Triton X-100) with $1 \%$ normal goat serum. Sections were then rinsed with PBS-T and incubated in secondary antibody (Alexa Fluor 594 goat anti-mouse, 1:500) with PBS-T for $4 \mathrm{~h}$ at room temperature. After PBS rinse, sections were coverslipped with Prolong Gold Antifade reagent with DAPI. To visualize laminar distributions of D1R, $\mathrm{D} 2 \mathrm{R}$, or D3R expression, fluorescence of mPFC sections was acquired with a spinning disk confocal microscope ( $10 \times$ objective, 0.3 numerical aperture, NA). Somatic fluorescence expression was assessed with a $z$-series from a $500 \times 800 \mu \mathrm{m}$ area of $\mathrm{mPFC}$ (long axis perpendicular to midline pia).

For analysis of cellular laminar distributions, laminar depths were used as defined previously by the L3 and L5b markers Cux1 and Ctip2. Given variability in L1 depth, laminar boundaries were defined with respect to the L1/2 border, visualized with DAPI. The bottom of L2/3, L5a, and L5b were defined as 119, 241, and $534 \mu \mathrm{m}$ from the L1/2 border, respectively (DeNardo et al., 2015).

For orthograde tracing experiments, P28 D3-Cre::Ai14 mice were injected with $300 \mathrm{nl}$ of AAV- EF1 $\alpha$-DIO-ChR2-EYFP in the mPFC (coordinates as above). Three weeks after injection, animals were perfused and the full brain fixed overnight. Then, $50-\mu \mathrm{m}$-thick coronal sections of the entire brain were obtained. To assess axonal projection patterns, fluorescent images were taken with a high-speed wide-field microscope (Nikon
Ti with Andor Zyla 5.2 camera, $10 \times$ objective, $0.45 \mathrm{NA}$ ) and then digitally stitched with ImageJ to reconstruct each full coronal section.

For retrograde tracing experiments, P52 + D3-Cre::Ai14 mice were injected with 200-300 nl of Alexa Fluor 488 conjugated to cholera toxin subunit B (Ctb-488) in the mPFC (coordinates as above), nucleus accumbens core (NAcc) (AP, +1.5; ML, -1.3; DV, -4.38), basolateral amygdala (BLA) (AP, $-1.55 ; \mathrm{ML},-2.95 ; \mathrm{DV},-5)$, or mediodorsal (MD) thalamus (AP, -1.7 ; ML, -0.3 ; DV, -3.45 ). Then, $3-4 \mathrm{~d}$ after injection, animals were perfused, the full brain fixed overnight, and $50-\mu \mathrm{m}$-thick coronal mPFC sections were obtained. In a subset of animals, paracoronal slices were prepared containing $\mathrm{mPFC}$ and slices were fixed, cryoprotected in a sucrose-PBS solution, and then sectioned on a freezing stage microtome at $50 \mu \mathrm{m}$ after a recording session. In both cases, the injection site was verified in $75 \mu \mathrm{m}$ coronal sections. To examine colabeling of Ail4 marker and retrograde tracer, fluorescence of mPFC sections was acquired with a confocal microscope ( $10 \times$ objective, $0.45 \mathrm{NA})$. Ai14/ Ctb-488 coexpression was assessed with a $z$-series taken of a 400-500 $\mu \mathrm{m}$ swath of mPFC up to $800 \mu \mathrm{m}$ from the pia. Analysis of laminar distribution was done as described above.

Two-photon imaging. A two-photon imaging system (Prairie Technologies) was used as described previously (Bender et al., 2010). A Chameleon Ultra II laser (Coherent Technologies) was tuned to $810 \mathrm{~nm}$. Epifluorescence and transfluorescence signals were captured through a $60 \times, 1.0$ NA objective and a 1.4 NA oil-immersion condenser (Olympus). Fluorescence was split into red and green channels using dichroic mirrors and band-pass filters (T560LPXR, ET525/50, ET620/60; Chroma). Green fluorescence (Fluo-5F) was captured with H10770PA-40 photomultiplier tubes (PMTs; Hamamatsu). Red fluorescence (Alexa Fluor 594) was captured with R9110 PMTs. Data are presented as averages of 10-20 events per site and are expressed as $\Delta(G / R) /(G / R)_{\text {sat }} * 100$ (simply, $\Delta\left(G / G_{\text {sat }}\right)$, where $(G / R)_{\text {sat }}$ was the maximal fluorescence in saturating $\mathrm{Ca}^{2+}(2 \mathrm{mM}) . \mathrm{Ca}^{2+}$ transient peaks were calculated from exponential fits to the fluorescence decay after stimulus offset. Two-photon imaging was performed in $\mathrm{P} 30-\mathrm{P} 45$ mice.

Chemicals. Fluo-5F pentapotassium salt, Alexa Fluor 594 hydrazide $\mathrm{Na}^{+}$salt, cholera toxin conjugated to Alexa Fluor 488, and Alexa Fluor 594 goat anti-mouse secondary antibody were from Invitrogen. BlockAid blocking solution was from Thermo Fisher Scientific. Anti-RFP (mouse) monoclonal antibody was obtained from Rockland Immunochemicals (200-301-379). Prolong Gold Antifade reagent with DAPI was from Invitrogen. All AAV vectors were obtained from the University of North Carolina vector core. SR95531, R-CPP, NBQX (-)-quinpirole hydrochloride, TTX, and GR103691 were from Tocris Bioscience. All others were from Sigma-Aldrich.

Statistics. All data are shown as mean \pm SEM. Depending on data distributions, an ANOVA followed by multiple two-sample $t$ tests or Kruskal-Wallis followed by Wilcoxon's rank-sum test (Holm-Sidak corrections for multiple comparisons) was used unless otherwise noted (significance: $p<0.05$ ). For the Wilcoxon's rank-sum test, $z$-statistics are given for large sample sizes $(n>20)$; otherwise, the rank-sum test statistic $(\mathrm{W})$ is reported.

\section{Results \\ D3Rs are expressed in a distinct subset of mPFC pyramidal cells}

To determine how D3Rs are distributed relative to known pyramidal cell classes in $\mathrm{mPFC}$, we visualized the distribution of fluorescently labeled pyramidal cells across mPFC layers using previously described border demarcations (Hooks et al., 2011; DeNardo et al., 2015) and dopamine-receptor-specific reporter mice (D1-tdTomato/D2-GFP or D1-tdTomato/D3-cre mice, as well as D2-Cre or D3-Cre mice either crossed to Ai14 or injected with a DIO-EYFP or DIO-mCherry virus). D1R- and D2Rexpressing $(\mathrm{D} 1+, \mathrm{D} 2+)$ pyramidal cells have been identified previously in L5, with morphological features consistent with thin- and thick-tufted pyramidal classes, respectively (Gee et al., 2012; Seong and Carter, 2012). Consistent with this, D1+ and 
A

A
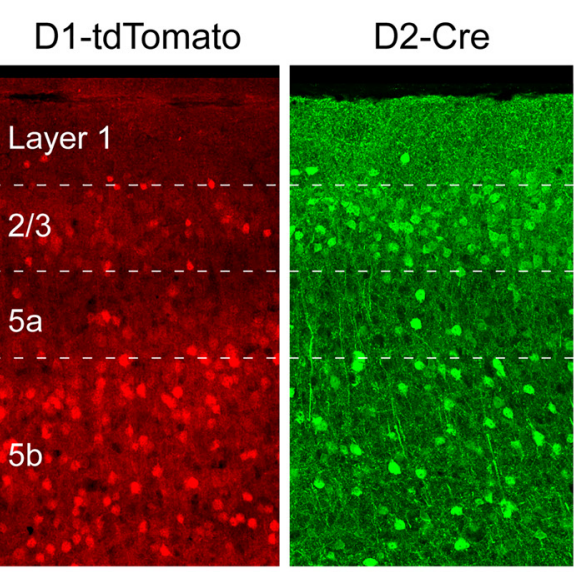

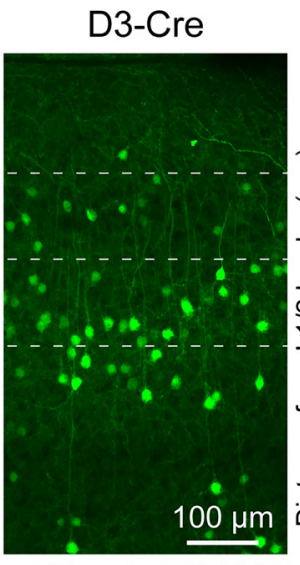

tdTomato DIO-EYFP

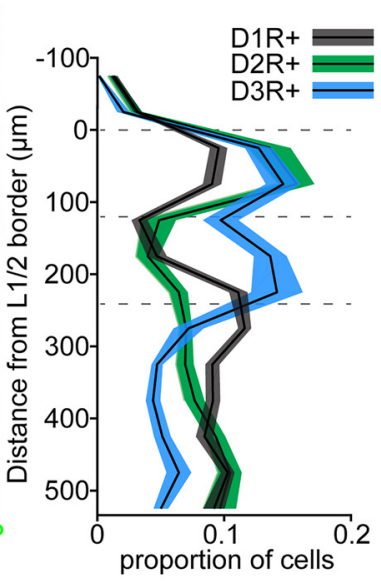

B

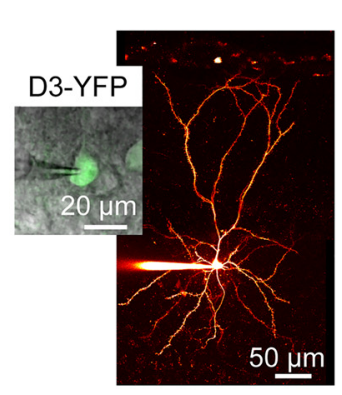

D1

D2 D3

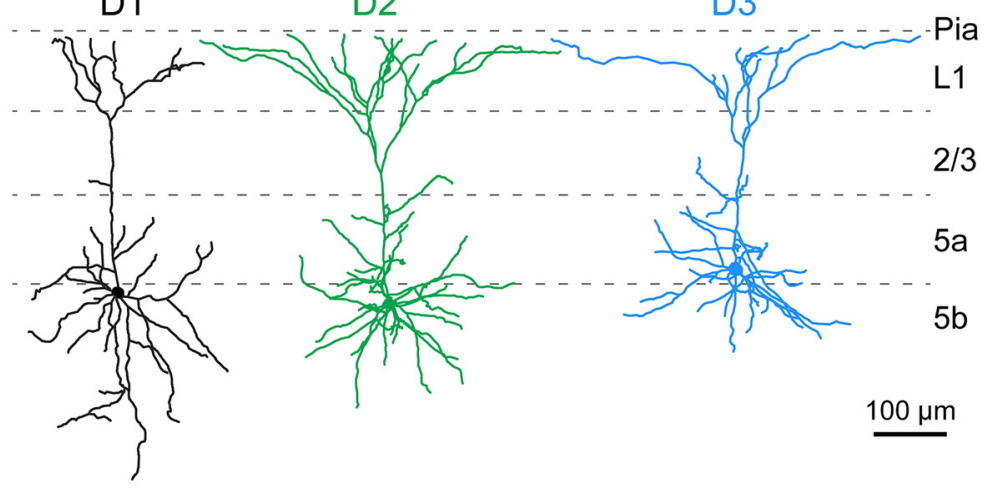

C<smiles>CC(C)CBr</smiles>

D2<smiles>CCC(C)C(C)C</smiles>

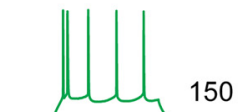

150

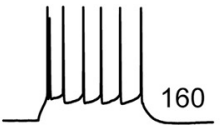

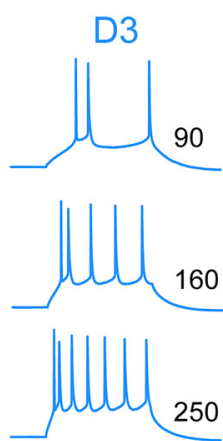

D

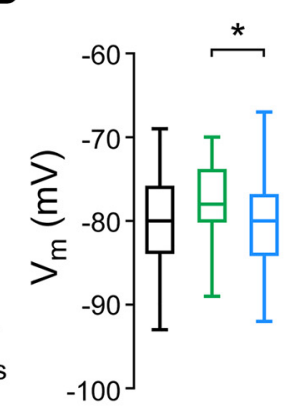

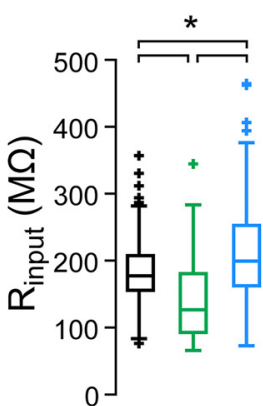

Figure 1. Laminar distribution, morphology, and intrinsic membrane properties of $\mathrm{D} 1+, \mathrm{D} 2+$, and $\mathrm{D} 3+\mathrm{L} 5$ pyramidal cell classes in $\mathrm{mPFC}$. $A$, Left, Schematic of coronal brain slice; red rectangle highlights mPFC recording region. Middle, Coronal mPFC sections showing fluorescently labeled (tdTomato or EYFP) D1R-, D2R-, or D3R-expressing neurons from either D1-tdTomato/D3-cre or D2-cre mice after AAV-DI0-EYFP injection. Laminar boundaries are designated with dashed white lines. Right, Distribution of D1+, D2+, and D3+ somatic distances from L1/2 border normalized to total fluorescently labeled cells within each mPFC section. Distributions for each cell type pooled from 3 D1-tdTmt/D3-cre animals and 3 D2-cre animals, 3 slices/animal. Solid line with shaded region indicates mean \pm SEM. $B$, Left, 2PLSMz-projection of $\mathrm{MPFC}$ D3 + pyramidal cell fluorescently identified via EYFP injection (inset). Right, Dendritic arbor reconstructions of L5 subtypes (D1+: black, D2+: green, D3+: blue; color code throughout figure). Reconstructions are aligned to midline pia. $C$, Example AP firing patterns in response to somatic current injection for all three cell classes (one set per class, injection amplitude noted to right of traces, $300 \mathrm{~ms}$ duration). D, Resting $V_{\mathrm{m}}$ and $R_{\text {in }}$ across cell classes. $R_{\text {in }}$ was assessed with -50 pA steps from rest. ${ }^{*} p<0.05$, Kruskal-Wallis, Wilcoxon rank-sum (Holm-Sidak correction); $n=95 / 35 / 188, \mathrm{D} 1+/ \mathrm{D} 2+/ \mathrm{D} 3+$. Boxplots are median, $25^{\text {th }}(\mathrm{Q} 1)$, and $75^{\text {th }}(\mathrm{Q} 3)$ percentiles; whiskers extend to all data points that are not outliers. Outliers are defined as $\mathrm{Q3}+1.5^{*}(\mathrm{Q3}-\mathrm{Q1})$ and $\mathrm{Q1}-1.5^{*}(\mathrm{Q3}-01)$.

D2 + neurons were identified in L5. In addition, D1+ and D2+ neurons were observed in L2/3. D2 + neurons were most heavily concentrated in L5b, with lower relative abundance in L5a. In contrast, D3R-expressing (D3+) neurons were concentrated within the upper cortical layers to the L5a/L5b border, with relatively low expression below (Fig. 1A).

That $\mathrm{D} 1+, \mathrm{D} 2+$, and $\mathrm{D} 3+$ neurons are distributed in distinct lamina suggests that they are restricted to separate mPFC pyramidal cell classes. To determine whether dopamine receptor expression correlates with electrophysiological or morphological characteristics, whole-cell current-clamp recordings were made from each of these cell classes and a series of hyperpolarizing and depolarizing pulses were delivered to examine subthreshold and suprathreshold voltage responses. Cells were simultaneously filled via patch pipettes with the red volume marker Alexa Fluor 594 and two-photon-based $z$-stacks were acquired over the entire dendritic span, allowing for post hoc morphological reconstruction.

Previous studies have shown that different prefrontal pyramidal cell classes express varying degrees of hyperpolarizationactivated cyclic nucleotide-gated (HCN) channels, which can 
influence resting membrane properties (Dembrow et al., 2010; Gee et al., 2012; Seong and Carter, 2012). We found that D1+, $\mathrm{D} 2+$, and D3+ neurons had different input resistances when subjected to a $-50 \mathrm{pA}$ current pulse (D1+: $183 \pm 5 \mathrm{M} \Omega, n=95$; $\mathrm{D} 2+: 146 \pm 11 \mathrm{M} \Omega, n=35 ; \mathrm{D} 3+: 212 \pm 5 \mathrm{M} \Omega, n=188$; Kruskal-Wallis, $H_{(2)}=32.91, p=7 \times 10^{-8}$; Wilcoxon's ranksum test, Holm-Sidak correction, D1+ vs D2+: $z=3.75$, D1+ vs D3+: $z=-3.32, \mathrm{D} 2+$ vs D3+: $z=-5.01 ; p<0.05)$ and that $\mathrm{D} 2+$ cell resting $V_{\mathrm{m}}$ was modestly depolarized relative to $\mathrm{D} 3+$ cells (D1+: $-80.0 \pm 0.6 \mathrm{mV}$; D2+: $-77.9 \pm 0.7 \mathrm{mV}$; D3+: $-80.2 \pm 0.4 \mathrm{mV}$; Kruskal-Wallis, $H_{(2)}=7.26, p=0.027$; Wilcoxon's rank-sum test, Holm-Sidak correction, D2+ vs D3+: $z=$ 2.76; $p<0.05$; Fig. $1 D$ ). Intrinsic membrane properties were stable within each class across the age range studied, consistent with other reports in rodent neocortex (McCormick and Prince, 1987; Zhang, 2004; linear regression of $V_{\mathrm{m}}$ or $R_{\mathrm{in}}$ vs age for D1+/ $\left.\mathrm{D} 2+/ \mathrm{D} 3+: r^{2}<0.01, p>0.4\right)$.

Larger current pulses $(-400 \mathrm{pA})$ more effectively recruit $\mathrm{HCN}$ current and reveal different response properties across dopamine-receptor-expressing classes. Consistent with other reports from D2 + neurons (Gee et al., 2012), 74\% of D2 + neurons exhibited a prominent voltage sag during hyperpolarizing pulses and had a voltage rebound that depolarized past rest after current offset. A far lower proportion of D1+ and D3+ neurons had similar response properties ( $4 \%$ and $6 \%$, respectively, defined by a peak rebound voltage occurring within $90 \mathrm{~ms}$ of current offset; Fig. 2A: rebound: $n=85 / 35 / 185, \mathrm{D} 1+/ \mathrm{D} 2+/ \mathrm{D} 3+$; KruskalWallis, $H_{(2)}=67.01, p=3 \times 10^{-15}$; Wilcoxon's rank-sum test, Holm-Sidak correction, D1 + vs D2 $+: z=5.89, \mathrm{D} 1+$ vs D3+: $z=-4.55$, D2+ vs D3+: $z=-7.08$; sag: $n=95 / 35 / 188, \mathrm{D} 1+$ / D2+/D3+; Kruskal-Wallis, $H_{(2)}=90.23, p=3 \times 10^{-20}$; Wilcoxon's rank-sum test, Holm-Sidak correction, D1+ vs D2+: $z=6.06, \mathrm{D} 1+\mathrm{vs} \mathrm{D} 3+: z=-5.51, \mathrm{D} 2+\mathrm{vs} \mathrm{D} 3+: z=-8.34)$. Therefore, we used these response properties to classify cells that likely express D2Rs, but lack D1Rs and D3Rs (termed Type 2).

To determine whether non-Type 2 neurons had electrophysiological phenotypes that correlated with D1R and D3R expression, we examined additional aspects of their intrinsic excitability. We found that multiple features differed across D1+ and D3+ groups; however, no single electrophysiological property was sufficient to discriminate these groups well. Therefore, we applied LDA to determine whether a combination of features would better distinguish $\mathrm{D} 1+$ and $\mathrm{D} 3+$ neurons. We chose five electrophysiological properties that allowed for maximal separation of D1+ and $\mathrm{D} 3+$ populations (Fig. 2C). These included sag amplitude in response to $-400 \mathrm{pA}$ current steps, rebound time constant during recovery from these current steps, and three spiking properties (AP rate of rise, threshold, and changes in interspike interval during an AP train). Compared with D1+ neurons, D3+ neurons had lower sag and slower rebound recovery after $-400 \mathrm{pA}$ current pulses (sag, D1+: $-2.7 \pm 0.1 \mathrm{mV}, n=92 ; \mathrm{D} 3+:-1.9 \pm$ $0.1 \mathrm{mV}, n=176$; two-sample $t$ test, $t_{(266)}=-4.62, p=6 \times 10^{-6}$; rebound $\tau, \mathrm{D} 1+: 30.1 \pm 0.6 \mathrm{~ms} ; \mathrm{D} 3+: 35.7 \pm 0.4 \mathrm{~ms}$; two-sample $t$ test, $\left.t_{(266)}=-7.56, p=7 \times 10^{-13}\right)$. In addition, $\mathrm{D} 3+$ neurons had a lower instantaneous spike frequency at train onset, slower $\mathrm{AP}$ rise times, and a larger increase in AP threshold of successive spikes in trains (Fig. 2B,C: statistics for classifier shown; twosample $t$ tests, $n=47 / 72, \mathrm{D} 1+/ \mathrm{D} 3+$; rebound: $t_{(118)}=-7.24$, $p=5 \times 10^{-11}$; sag: $t_{(118)}=-3.77, p=3 \times 10^{-4}$; doublet index: $t_{(118)}=7.49, p=1 \times 10^{-11}$; AP rate of rise: $t_{(118)}=6.98, p=2 \times$ $10^{-10}$; $\Delta$ Threshold: $\left.t_{(118)}=-7.65, p=6 \times 10^{-12}\right)$. Additional features also differed across these populations, but they tended to covary with parameters already included in the analysis and therefore did not improve discriminability (Fig. 3).

Using these features, we created multiple LDA classifiers to assess the electrophysiological discriminability of these populations and to allow for classification of nonfluorescent neurons (see Materials and Methods, Fig. 2, Tables 1 and 2). To evaluate our electrophysiological model's performance, we implemented holdout cross-validation and found that the classifiers' mean accuracies in predicting D1R or D3R expression always exceeded $70 \%$ (D1+ range: $80-93 \%$, median: $87 \%$; D3 + range: $72-87 \%$, median: $80 \%$, Fig. $2 E$ ). These data indicate that pyramidal cells expressing different dopamine receptors tend to have distinct intrinsic electrophysiological phenotypes and that $\mathrm{D} 1+$ and $\mathrm{D} 3+$ neurons comprise generally nonoverlapping populations. We confirmed this separation by injecting D1-tdTomato/D3-cre mice with an AAV vector containing Cre-dependent EYFP, enabling simultaneous visualization of D1R and D3R expression via tdTomato and EYFP fluorescent markers, respectively (Fig. 4A). Consistent with electrophysiological analysis, D1+ and D3+ cells were largely separate populations, with $>90 \%$ of labeled cells within L5 uniquely expressing the D1R or D3R (Fig. 4C).

The ability to identify accurately neurons likely to express a given dopamine receptor based solely on electrophysiological characteristics would be useful for assessing dopaminergic function in cases in which fluorescent reporters are not available. To enhance the prediction accuracy that a neuron's electrophysiological signature indeed corresponds to expression of D1R or D3R, we defined an "exclusion zone," an area surrounding the decision boundary defined by the discriminant, in which D1+ and D3 + cell classes' electrophysiology overlapped (see Materials and Methods; Fig. 2D). Across all classifiers, this yielded a median accuracy of $>90 \%$ for both D1 + and D3 + cells when tested on the final classifier that included all genetically identified cells (Fig. $2 E)$. Therefore, by rejecting a subset of cells with overlapping electrophysiological characteristics, D1+ and D3+ cells can be categorized with high accuracy. We then applied this final set of classifiers to all non-Type 2, nongenetically identified neurons, categorizing them as Type 1, Type 3, or "unidentified." By this method, $89 \%$ of 103 neurons analyzed were categorized as Type 1 or Type 3.

After electrophysiological characterization of D1+, D2+, and D3 + cell classes, we analyzed our post hoc morphological reconstructions to determine whether these cell classes were also morphologically distinct. D1+ neurons had relatively simple apical dendritic morphology (Fig. 1B, Table 3), consistent with previous reports of D1+ "thin-tufted" pyramidal cells (Seong and Carter, 2012). D2+ neurons had much more complex apical tuft morphology, both with respect to their broad span as well as overall apical dendritic length and branch points, similar to the "thicktufted” D2+ neurons described previously (Gee et al., 2012). In contrast, D3 + pyramidal cells in L5 had a morphology that was intermediate to D1+ and D2+ neurons; they had an apical tuft that spanned a similar distance as D2 + pyramidal cells, but had branching and dendritic arbor length more comparable to D1+ neurons. In addition, for most morphological measures, D3+ and Type 3 neurons (genetically unlabeled) were identical (Table $3)$. Overall, these data suggest that there are electrophysiologically and morphologically distinct L5 pyramidal cell classes in $\mathrm{mPFC}$ and that these different classes correlate with expression of the $\mathrm{D} 1, \mathrm{D} 2$, and $\mathrm{D} 3$ receptors. 
A

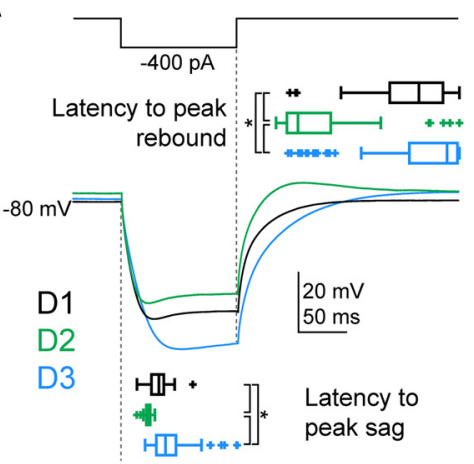

B

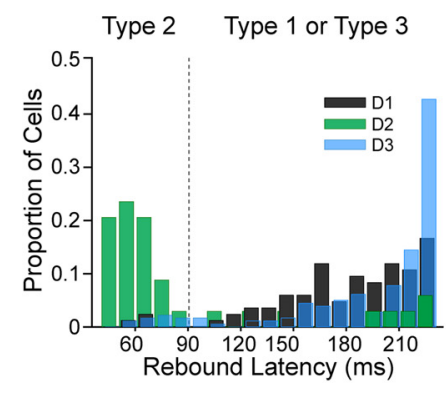

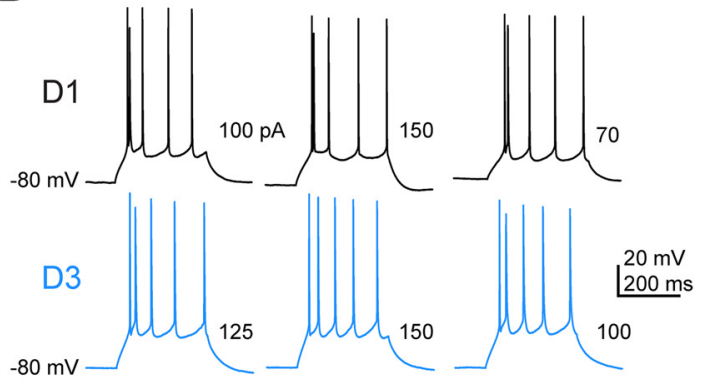

C

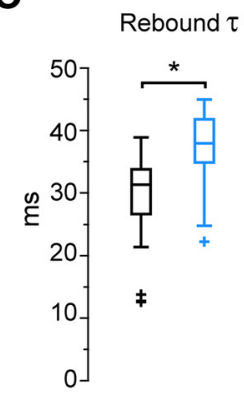

Sag Amplitude

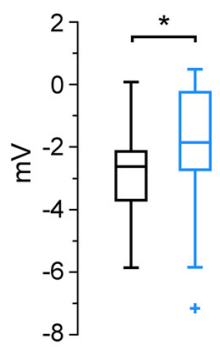

Doublet Index

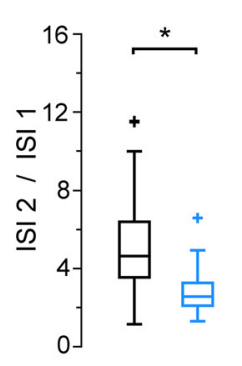

D

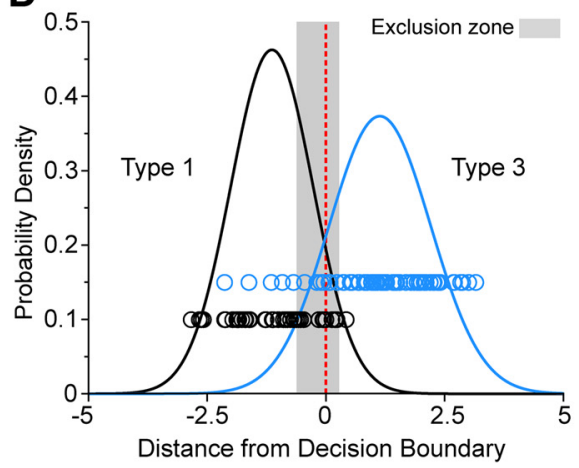

E

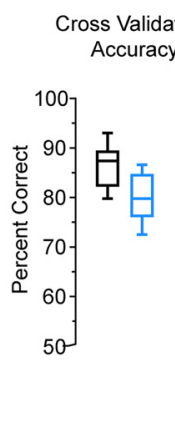

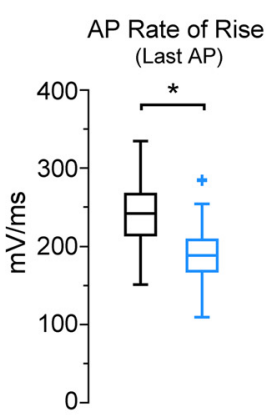

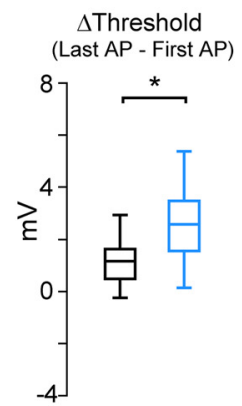

F
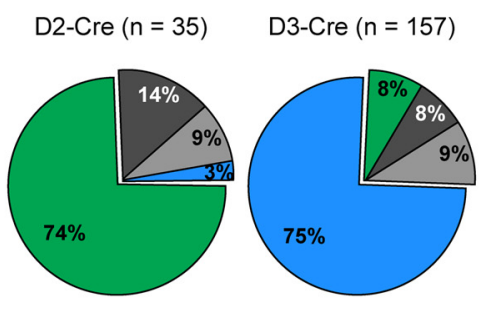

Type 1 Type 2 Type 3 Unclassified

Figure 2. Electrophysiological classification of $\mathrm{D} 1+, \mathrm{D} 2+$, and $\mathrm{D} 3+$ pyramidal cell classes. $A$, Left, Responses to $-400 \mathrm{pA}$ hyperpolarizing steps differ between cell classes (D1+: black, $\mathrm{D} 2+$ : green, $\mathrm{D} 3+$ : blue; color code same in $\boldsymbol{B}-\boldsymbol{E}$ ). Boxplots quantify latency to peak rebound (maximum voltage relative to baseline after current offset) and latency to peak voltage sag (maximum voltage relative to steady-state after current onset). ${ }^{*} p<0.05$, Kruskal-Wallis, Wilcoxon rank-sum, Holm-Sidak correction; rebound: $n=85 / 35 / 185, \mathrm{D} 1+/ \mathrm{D} 2+/ \mathrm{D} 3+;$ sag: $n=95 / 35 / 188, \mathrm{D} 1+/$ $D 2+/ D 3+$. Right, Histogram of rebound latency by cell type. Dotted line represents cutoff between Type 2 and Type 1/Type 3 neurons. B, Example responses to somatic current injection in D1+ and D3 + neurons (three per class, amplitudes noted to right of traces). C, Electrophysiological features used for linear discriminant classifiers, shown for classification of five AP spike trains with Fluo-5F-based internal solution. D1 + and D3 + cell classes differ between all five parameters, which include responses to both hyperpolarizing (sag and rebound) and depolarizing (spike train properties) somatic current injection. ${ }^{*} p<0.05$, two-sample $t$ test; $n=47 / 72, \mathrm{D} 1+/ \mathrm{D} 3+$. D, Visualization of linear discriminant classifier (as in C) with individual D1 + and D3 + cells (circles) plotted with respect to Euclidean distance from the discriminant decision boundary (red dashed line). These distances were fit by normal distributions, which defined the "exclusion zone," the area near the discriminant where cell classes are imperfectly separated and therefore "unidentified" (see Materials and Methods). $\boldsymbol{E}$, Left, Results of holdout cross-validation for all 12 discriminant classifiers in predicting D1R or D3R expression. Right, Percentage accuracy of final models with "unclassified" D1 + and D3 + cells removed due to the exclusion zone. $\boldsymbol{F}$, Percentage of fluorescent cells in D1-tdTomato, D2-Cre, and D3-Cre lines classified as Type 1, Type 2, Type 3, or unidentified. (Type 1: dark gray, Type 2: green; Type 3: blue; unidentified: light gray).

\section{L5 D3+ pyramidal neurons are an IT, cortically projecting neuronal subtype}

Cortical pyramidal neurons are categorized into two broad projection classes: IT, cortically projecting neurons and PT, subcortically projecting neurons. Whereas IT neurons are distributed throughout L5, PT neurons are restricted to L5b (Molnár and Cheung, 2006; Shepherd, 2013). In the mPFC, L5 D1+ and D2+ neurons correspond to IT and PT subtypes, respectively, with D1R-expressing cells projecting to contralateral cortex and D2Rexpressing cells projecting subcortically (Dembrow et al., 2010; Gee et al., 2012). Interestingly, although D3Rs are a member of the D2 family, their density in L5b is low. This suggests that they may have different long-range synaptic targets than other types of D2-family-expressing neurons.

To determine the downstream targets of $\mathrm{D} 3+$ pyramidal neurons, we injected DIO-ChR2-EYFP into the mPFC of D3-Cre mice (Fig. $5 A$ ), allowing visualization of axonal projections throughout the brain. Axons were prominent in the contralateral $\mathrm{mPFC}$, bilateral BLA, bilateral ventral striatum, including the NAcc, and both $\mathrm{MD}$ and ventromedial thalamus (Fig. $5 B-D$ ), indicating that $\mathrm{D} 3+$ neurons project to diverse cortical and subcortical targets. However, viral transfection was not limited to D3 + neurons in L5; rather, D3 + neurons throughout cortical lamina were transfected (Fig. 5A). Therefore, we complemented these ortho- 

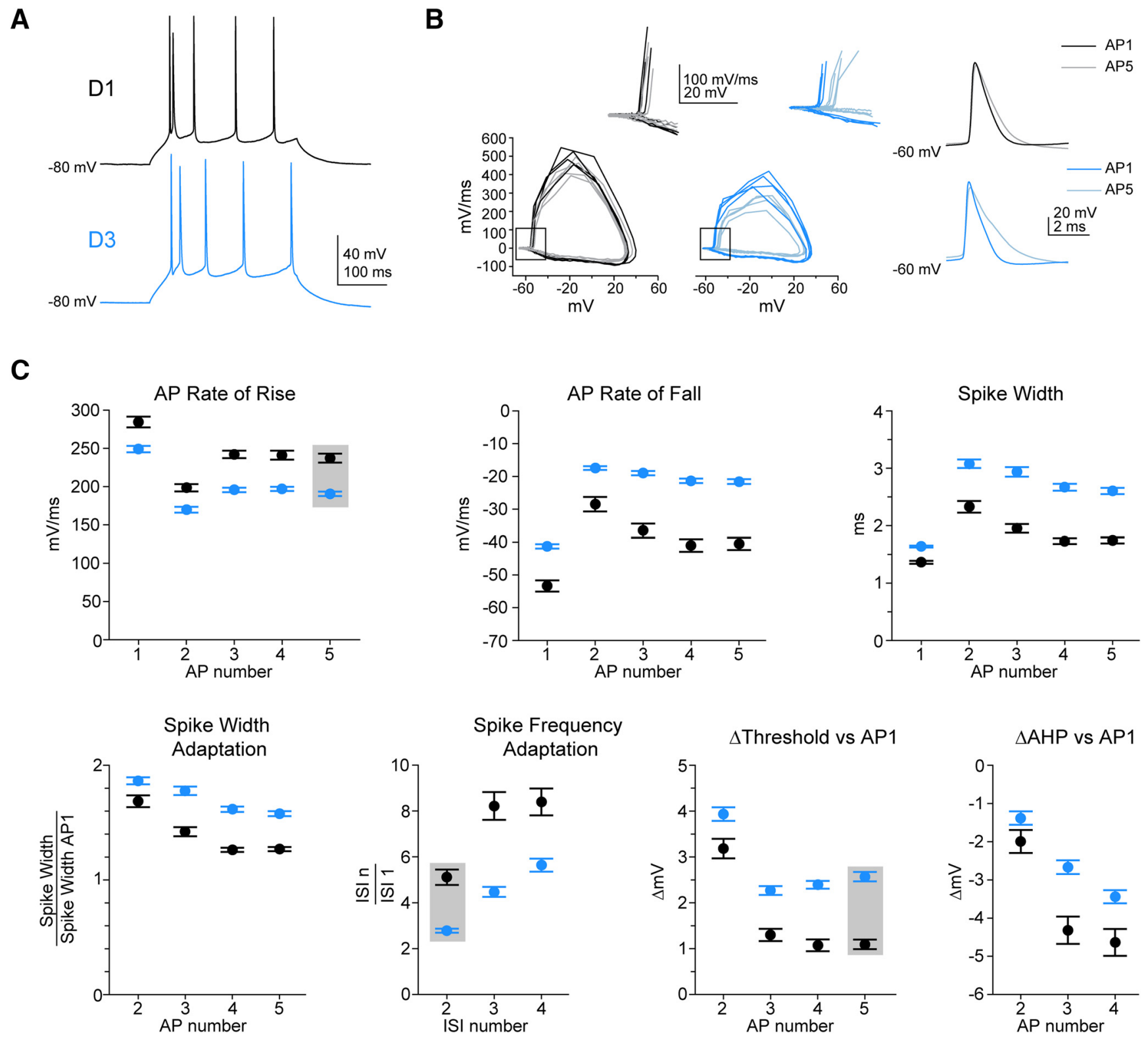

Figure 3. $\mathrm{D} 1+$ and $\mathrm{D} 3+\mathrm{mPFC}$ pyramidal classes differ in AP waveform and AP spike train properties. $A$, Example spike trains from somatic current injection in D1+ (black) and D3 + (blue) neurons. Color code throughout figure. All analyses in this figure are for five AP spike trains from 300 ms current injections with Fluo-5F in the internal solution. $\boldsymbol{B}$, Left, Phase plane plots demonstrate shifting AP threshold in D3 + cell class, but not in D1 + cell class (see insets). Right, Example changes in AP waveform across a five AP spike train for D1 + and D3 + cell classes. C, AP waveform and AP spike train properties differ between D1+ and D3 + cell classes. Gray boxes indicate parameter chosen for discriminant analysis; $n=47 / 72, \mathrm{D} 1+/ \mathrm{D} 3+$. Error bars indicate mean \pm SEM.

grade tracing experiments with injections of fluorescently conjugated cholera toxin $\mathrm{B}$, which incorporates into axonal terminals and transports retrogradely to somata. Alexa Fluor 488 conjugated cholera toxin was injected into four putative downstream targets in D3-Cre::Ai14 animals: contralateral mPFC and ipsilateral BLA, NAcc, and MD thalamus (Fig. 6A, insets). We then examined the extent and laminar distribution of overlap between D3+ and retrogradely labeled cell populations (Fig. 6). Using these methods, we identified a substantial L5 D3+ projection to both the NAcc and the contralateral mPFC. Indeed, the probability that a cell projected to the NAcc or mPFC, given that it was D3R-expressing, was $\sim 52 \%$ and $\sim 24 \%$, respectively. In contrast, there was $<10 \%$ probability that a D3 + L5 cell projected to the MD thalamus, a target of D2 + L5 neurons (Gee et al., 2012; Fig. $6 C: n=7 / 10 / 8 / 9, \mathrm{mPFC} / \mathrm{NAcc} / \mathrm{BLA} / \mathrm{MD}$; ANOVA, $F_{(3,30)}=$ $39.24, p=2 \times 10^{-10}$; two-sample $t$ test, Holm-Sidak correction,
mPFC vs NAcc: $t_{(15)}=-4.77, \mathrm{mPFC}$ vs BLA: $t_{(13)}=3.10, \mathrm{mPFC}$ vs MD: $t_{(14)}=3.78$, NAcc vs BLA, $t_{(16)}=7.76$, NAcc vs MD: $t_{(17)}$ $=8.55 ; p<0.05)$. Therefore, though both D2R and D3R are of the same receptor family, they have distinct downstream targets. Instead, L5 D3+ and D1+ neurons share a common projection to contralateral cortex, suggesting that corticocortical networks can be modified by both $\mathrm{G}_{\mathrm{s}}$ - and $\mathrm{G}_{\mathrm{i}}$-coupled dopamine receptor classes.

\section{Dopamine regulates AIS Ca and burst initiation in D3R-expressing neurons}

Recently, we found that D3Rs regulate a subset of Ca channels expressed in the AIS of auditory brainstem interneurons. Because pyramidal cells also express Ca channels in the AIS (Bender and Trussell, 2009; Yu et al., 2010), we investigated whether D3Rs had a similar function in the mPFC. Spike trains were evoked with 
Table 1. Coefficients for LDA

\begin{tabular}{|c|c|c|c|c|c|c|c|}
\hline Ca buffer & $\begin{array}{l}\text { No. of } \\
\text { APs }\end{array}$ & $\begin{array}{l}\text { Sag } \\
\text { amplitude }\end{array}$ & $\begin{array}{l}\text { Rebound time } \\
\text { constant }\end{array}$ & $\begin{array}{l}\text { Doublet index } \\
\text { (IS2/IS1) }\end{array}$ & $\begin{array}{l}\text { AP rate of } \\
\text { rise }\end{array}$ & $\begin{array}{l}\text { Threshold } \\
\text { change }\end{array}$ & Intercept \\
\hline \multicolumn{8}{|c|}{ Standardized linear coefficients ${ }^{a}$} \\
\hline \multirow[t]{6}{*}{ EGTA } & 3 & 0.552 & 0.381 & -0.089 & -1.826 & 0.036 & -0.043 \\
\hline & 4 & 0.000 & 0.329 & -0.653 & -1.664 & 0.943 & -0.082 \\
\hline & 5 & 0.211 & 0.279 & -0.844 & -1.285 & 1.058 & -0.117 \\
\hline & 6 & -0.111 & 0.578 & -1.009 & -1.750 & 0.612 & -0.194 \\
\hline & 7 & 0.369 & 0.192 & -0.998 & -1.785 & 1.479 & -0.589 \\
\hline & 8 & 0.537 & 0.345 & -0.883 & -1.162 & 1.736 & -1.029 \\
\hline \multirow[t]{6}{*}{ Flu05 } & 3 & 0.339 & 1.408 & -0.622 & -1.030 & 0.317 & 0.469 \\
\hline & 4 & 0.144 & 1.304 & -1.147 & -0.271 & 0.818 & 0.533 \\
\hline & 5 & 0.181 & 1.272 & -1.282 & -1.058 & 0.949 & 0.550 \\
\hline & 6 & 0.037 & 1.292 & -1.152 & -1.300 & 1.038 & 0.543 \\
\hline & 7 & -0.095 & 0.981 & -1.370 & -0.589 & 0.961 & -0.179 \\
\hline & 8 & 0.216 & 0.435 & -0.753 & -1.015 & 0.783 & -0.752 \\
\hline
\end{tabular}

${ }^{a}$ Standardized linear coefficients for all variables used for all LDA classifiers (3-8 APs with either EGTA or Flu05 in the internal solution).

Table 2. Mean \pm SD $^{a}$

\begin{tabular}{|c|c|c|c|c|c|c|c|}
\hline Ca buffer & $\begin{array}{l}\text { No. of } \\
\text { APs }\end{array}$ & $\begin{array}{l}\text { Sag } \\
\text { amplitude (mV) }\end{array}$ & $\begin{array}{l}\text { Rebound time } \\
\text { constant (ms) }\end{array}$ & $\begin{array}{l}\text { Doublet index } \\
\text { (IS2/IS1) }\end{array}$ & $\begin{array}{l}\text { AP rate of } \\
\text { rise }(V / s)\end{array}$ & $\begin{array}{l}\text { Threshold } \\
\text { change }(\Delta \mathrm{mV})\end{array}$ & $\begin{array}{l}\text { No. of } \\
\text { cells (D1; D3) }\end{array}$ \\
\hline \multirow[t]{6}{*}{ EGTA } & 3 & $-2.38 \pm 0.94$ & $32.53 \pm 4.55$ & $1.83 \pm 0.80$ & $229.23 \pm 46.01$ & $1.16 \pm 1.29$ & $34 ; 32$ \\
\hline & 4 & $-2.47 \pm 0.98$ & $32.30 \pm 4.47$ & $1.57 \pm 0.62$ & $234.56 \pm 51.99$ & $1.30 \pm 1.18$ & $36 ; 33$ \\
\hline & 5 & $-2.42 \pm 0.96$ & $32.56 \pm 4.37$ & $1.33 \pm 0.45$ & $220.07 \pm 47.18$ & $1.96 \pm 1.37$ & $35 ; 31$ \\
\hline & 6 & $-2.51 \pm 0.94$ & $32.21 \pm 4.20$ & $1.16 \pm 0.35$ & $216.11 \pm 46.95$ & $2.42 \pm 1.79$ & $35 ; 29$ \\
\hline & 7 & $-2.54 \pm 0.95$ & $31.79 \pm 4.48$ & $1.03 \pm 0.30$ & $213.77 \pm 38.19$ & $2.83 \pm 1.49$ & $36 ; 23$ \\
\hline & 8 & $-2.65 \pm 0.88$ & $31.47 \pm 3.63$ & $0.96 \pm 0.25$ & $211.66 \pm 35.28$ & $3.31 \pm 1.61$ & $34 ; 14$ \\
\hline \multirow[t]{6}{*}{ Flu05 } & 3 & $-2.12 \pm 1.48$ & $34.87 \pm 6.52$ & $1.68 \pm 0.83$ & $226.52 \pm 49.14$ & $0.83 \pm 1.28$ & $47 ; 85$ \\
\hline & 4 & $-2.13 \pm 1.55$ & $35.37 \pm 6.17$ & $1.38 \pm 0.66$ & $217.77 \pm 46.87$ & $1.38 \pm 1.06$ & $45 ; 78$ \\
\hline & 5 & $-2.21 \pm 1.50$ & $34.58 \pm 6.82$ & $1.18 \pm 0.50$ & $208.95 \pm 42.70$ & $1.99 \pm 1.24$ & $47 ; 72$ \\
\hline & 6 & $-2.29 \pm 1.38$ & $34.97 \pm 6.20$ & $1.04 \pm 0.37$ & $200.73 \pm 44.81$ & $2.62 \pm 1.47$ & $44 ; 65$ \\
\hline & 7 & $-2.39 \pm 1.50$ & $32.97 \pm 6.46$ & $0.99 \pm 0.31$ & $205.25 \pm 40.55$ & $2.93 \pm 1.44$ & $44 ; 37$ \\
\hline & 8 & $-2.55 \pm 1.39$ & $31.51 \pm 4.63$ & $1.00 \pm 0.24$ & $196.18 \pm 40.14$ & $3.32 \pm 1.50$ & $40 ; 15$ \\
\hline
\end{tabular}

${ }^{a}$ Mean and SD used to standardize data for classifiers (standardized data used for standardized linear coefficients).

somatic current injection $(3 \times 50 \mathrm{~Hz}, 1.5-2 \mathrm{nA}, 2$ ms per stimulus) and resultant axonal Ca transients were imaged 25-35 $\mu \mathrm{m}$ distal to the axon hillock. AIS Ca channel modulation was then assessed with the D2/D3R agonist quinpirole $(2 \mu \mathrm{M})$ in the presence of $10 \mu \mathrm{M}$ NBQX, $10 \mu \mathrm{M}$ R-CPP, and $10 \mu \mathrm{M}$ SR-95531. Although spike-evoked $\mathrm{Ca}$ influx was observed in the AIS of all three pyramidal subclasses, Ca influx was modulated only in fluorescently tagged D3+ neurons or neurons classified as Type 3 (Fig. $7 B$ : normalized $\Delta G / G_{\text {sat }}, \mathrm{D} 1+: 0.98 \pm 0.02, n=10$; Type 2: $1.00 \pm 0.03, n=4 ; \mathrm{D} 3+: 0.69 \pm 0.03, n=10$; Type 3: $0.72 \pm 0.03$, $n=10$; D3 + or Type 3 vs D1 + and Type $2 ; p<0.05$; ANOVA, two-sample $t$ tests, Holm-Sidak correction; see below for statistics). Quinpirole had no effect on AIS Ca in Type 3 neurons in $\mathrm{D} 3 \mathrm{R}^{-1-}$ mice or in wild-type mice in the presence of the D3R antagonist GR103691 (5 $\mu \mathrm{M})$ (Fig. $7 B$ : normalized $\Delta G / G_{\text {sat }}$, D3R ${ }^{-1-}: 1.02 \pm 0.03, n=5$; GR103691: $0.98 \pm 0.04, n=4 ; p<$ 0.05 vs quinpirole alone [statistical values for all comparisons shown in Fig. $7 B$ : ANOVA, $F_{(6,41)}=25.19, p=3 \times 10^{-12}$; twosample $t$ test, Holm-Sidak correction, Type 3 quinpirole vs Type 3 GR103691 + quinpirole, $t_{(12)}=-4.51$, Type 3 quinpirole vs Type $3 \mathrm{D} 3^{-1-}+$ quinpirole, $t_{(13)}=-5.90$, Type 3 quinpirole vs Type $3 \mathrm{Ca}_{\mathrm{v}} 3.2^{-1-}+$ quinpirole, $t_{(13)}=-4.85$, Type 3 quinpirole vs D $1+$ quinpirole, $t_{(18)}=7.05$, Type 3 quinpirole vs Type 2 quinpirole, $t_{(12)}=5.02$, D3 + quinpirole vs Type 3 GR103691 + quinpirole, $t_{(12)}=-5.88, \mathrm{D} 3+$ quinpirole vs Type $3 \mathrm{D} 3^{-1-}+$ quinpirole, $t_{(13)}=-7.54, \mathrm{D} 3+$ quinpirole vs Type $3 \mathrm{Ca}_{\mathrm{v}} 3.2^{-1-}+$ quinpirole, $t_{(13)}=-6.23, \mathrm{D} 3+$ quinpirole vs $\mathrm{D} 1+$ quinpirole, $t_{(18)}=9.00, \mathrm{D} 3+$ quinpirole vs Type 2 quinpirole, $t_{(12)}=$
-6.51]). Furthermore, AIS Ca was sensitive to endogenous dopamine because optogenetic stimulation of endogenous $\mathrm{TH}+$ fibers was sufficient to alter AIS Ca transients (TH-Cre::Ai32 mice, see Materials and Methods, Fig. $7 C$; normalized $\Delta G / G_{\text {sat }}$, ChR2 stimulation alone: $0.75 \pm 0.04, n=8$; stimulation in $1 \mu \mathrm{M}$ sulpiride: $0.93 \pm 0.03, n=4$; Wilcoxon's rank-sum test: $\mathrm{W}=40$, $p=0.04)$.

In previous work in auditory brainstem, we found that D3Rs specifically modulate $\mathrm{Ca}_{\mathrm{V}} 3$ calcium channels (Bender et al., 2010; Yang et al., 2016). Here, we found that AIS Ca was modulated only in D3+/Type 3 cells. This may reflect selective expression of $\mathrm{Ca}_{\mathrm{V}} 3$ channels in this cell class and not in D1+ or D2+ cells. To test this, we made voltage-clamp recordings with Cs-based internal, $500 \mathrm{~nm}$ TTX, and $1 \mathrm{~mm}$ Cs to block K, Na, and HCN channels, respectively, and imaged $\mathrm{Ca}$ influx in the AIS of fluorescently tagged cells (Fig. 7D). Putative $\mathrm{Ca}_{\mathrm{V}} 3$ current was isolated with voltage steps from $-100 \mathrm{mV}$ to $-50 \mathrm{mV}$. Interestingly, all 3 cell classes displayed comparable levels of AIS Ca influx (D1+: $3.6 \pm$ $0.6, n=6 ; \mathrm{D} 2+: 3.5 \pm 0.4, n=3 ; \mathrm{D} 3+: 3.4 \pm 1.2, n=8 ; \Delta G / G_{\text {sat }}$, ANOVA, $p=0.99$ ) even though whole-cell $\mathrm{Ca}_{\mathrm{V}} 3$ currents were smaller in D3 + cells (D1+: $-292 \pm 35 \mathrm{pA}$; D2+: $-271 \pm 58 \mathrm{pA}$; D3+: $-148 \pm 15$ pA; ANOVA, $F_{(2,14)}=8.03, p=0.005$; twosample $t$ test, Holm-Sidak correction, D1 + vs $\mathrm{D} 3+: t_{(12)}=$ $-4.14, \mathrm{D} 2+$ vs D3 $\left.+: t_{(9)}=-2.98 ; p<0.05\right)$. Whole-cell current and imaged $\mathrm{Ca}$ transients were sensitive to the selective $\mathrm{Ca}_{\mathrm{V}} 3$ antagonist TTA-P2 $(1 \mu \mathrm{M})$, indicating that $\mathrm{Ca}_{\mathrm{V}} 3$ channels are found throughout dendritic and AIS compartments in all classes (Fig. $7 D, E$ ). Despite similar AIS Ca channel expression across cell 


\section{A D1-tdTmt/D3-Cre (DIO-EYFP injection) tdTmt DIO-EYFP}
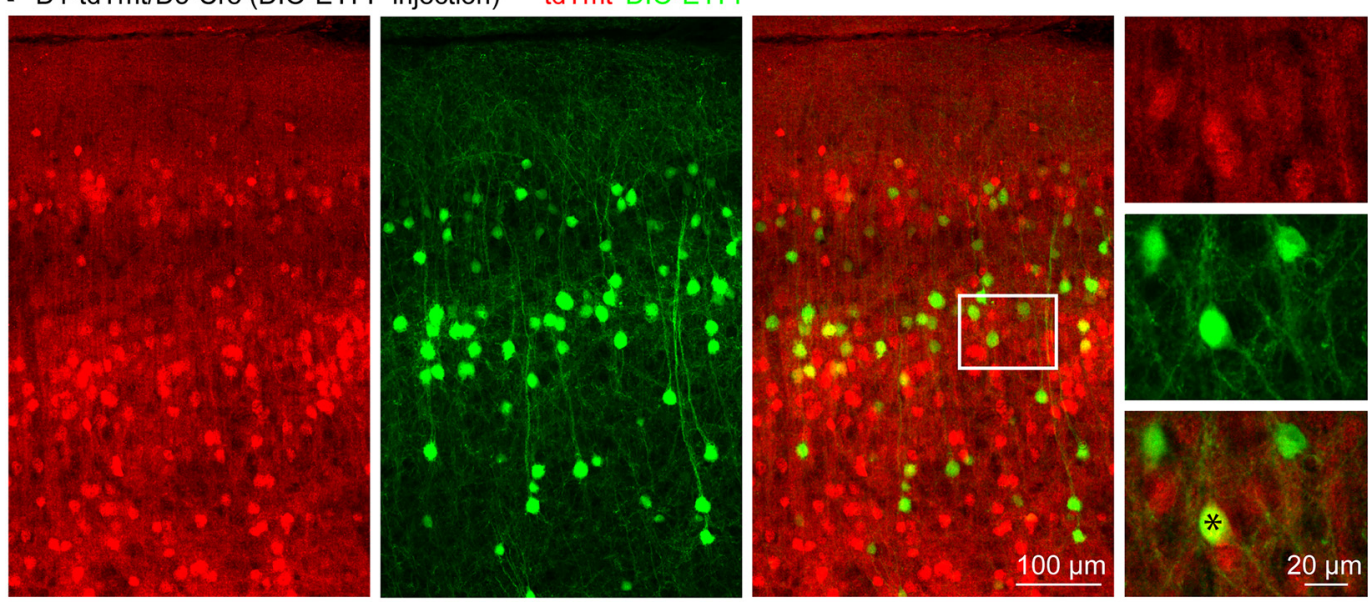

B

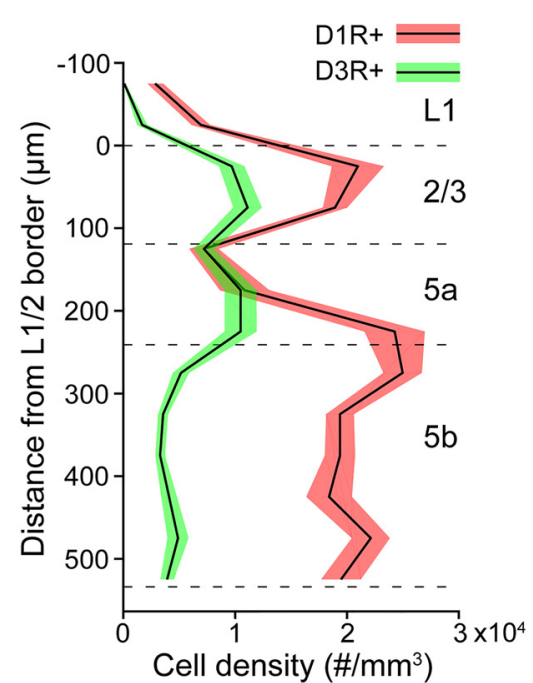

C

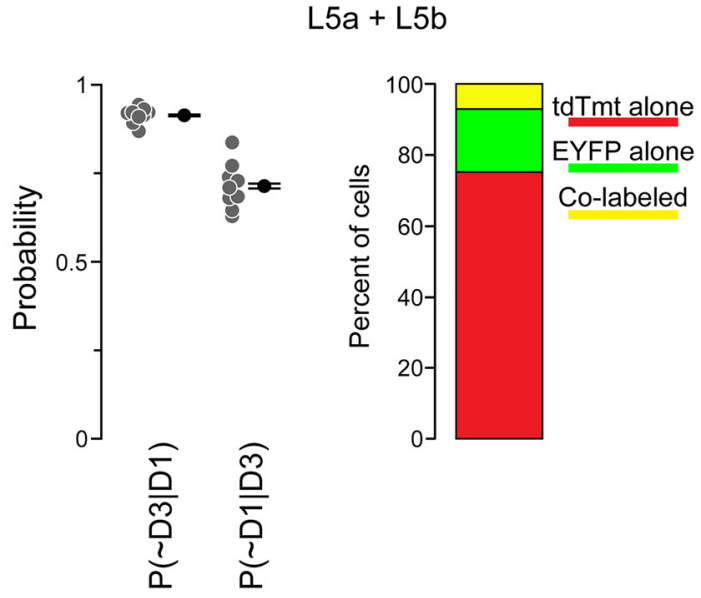

Figure 4. D1R and D3R expression in the mPFC occurs in largely separate cell populations. $A$, Confocal images of mPFC (maximal z-projection) from D1-tdTomato/D3-Cre mouse injected with AAV-DI0-EYFP. Right, Inset, Single optical section showing both single- and double-labeled cells. Asterisk denotes D1R and D3R colabeling. $\boldsymbol{B}$, Distribution of D1 + and D3 + somatic distances from L1/2 border as a function of cell density (data same as plotted in Fig. 1A). Distributions for each cell type were pooled from three injections with three slices/animal. Solid line with shaded region indicates mean \pm SEM. C, Left, Probability that a D1R- or D3R-expressing neuron lacks coexpression of the other receptor. Gray circles are single mPFC sections (three animals, three sections/animal), black circles are mean \pm SEM. Right, tdTomato, EYFP, and colabeled cells as a percentage of all labeled cells within L5.

Table 3. Morphology of pyramidal cell classes

\begin{tabular}{|c|c|c|c|c|c|}
\hline Morphological property & $\mathrm{D} 1(n=11)$ & $\mathrm{D} 2(n=10)$ & D3 $(n=29)$ & Type 3 (Т3) $(n=33)$ & $\begin{array}{l}\text { Significant comparisons } \\
(p<0.05)\end{array}$ \\
\hline Tuft width ( $\mu \mathrm{m})$ & $195.46 \pm 17.93$ & $345.94 \pm 30.74$ & $287.67 \pm 19.81$ & $280.48 \pm 14.60$ & $\mathrm{D} 2, \mathrm{D} 3, \mathrm{~T} 3>\mathrm{D} 1$ \\
\hline \multicolumn{6}{|l|}{ Dendritic length $(\mathrm{mm})$} \\
\hline Apical & $1.66 \pm 0.20$ & $2.82 \pm 0.36$ & $1.67 \pm 0.11$ & $1.70 \pm 0.12$ & $\mathrm{D} 2>\mathrm{D} 1, \mathrm{D} 3, \mathrm{~T} 3$ \\
\hline Basal & $1.41 \pm 0.20$ & $2.14 \pm 0.12$ & $2.16 \pm 0.13$ & $1.56 \pm 0.09$ & $\mathrm{D} 2, \mathrm{D} 3>\mathrm{D} 1, \mathrm{~T} 3$ \\
\hline \multicolumn{6}{|l|}{ Branch points (no.) } \\
\hline Apical & $10.27 \pm 1.30$ & $18.50 \pm 2.28$ & $10.14 \pm 0.77$ & $9.79 \pm 0.88$ & $\mathrm{D} 2>\mathrm{D} 1, \mathrm{D} 3, \mathrm{~T} 3$ \\
\hline Basal & $5.45 \pm 0.86$ & $13.40 \pm 1.39$ & $12.48 \pm 0.71$ & $8.48 \pm 0.53$ & $\mathrm{D} 2, \mathrm{D} 3>\mathrm{T} 3>\mathrm{D} 1$ \\
\hline Apical obliques (no.) & $4.45 \pm 0.67$ & $7.10 \pm 1.09$ & $2.31 \pm 0.27$ & $2.21 \pm 0.25$ & D1, D2 > D3, T3 \\
\hline Pia to soma ( $\mu \mathrm{m})$ & $359.45 \pm 9.85$ & $405.53 \pm 11.69$ & $306.24 \pm 6.24$ & $302.16 \pm 7.75$ & $\mathrm{D} 2>\mathrm{D} 1>\mathrm{D} 3, \mathrm{~T} 3$ \\
\hline
\end{tabular}

Morphological parameters of D1+, D2+, D3+, and Type 3 (T3) pyramidal neuron subclasses. Parameters are as follows. Tuft width ( $\mu \mathrm{m}$ ) was determined as the diameter of a circle parallel to pia that encompasses all $\mathrm{L} 1$ tuft dendrites. Dendritic length was the overall length of dendritic apical and basal structures. "Apical" includes the primary apical dendrite, all apical obliques, and apical tuft. Total number of branch points was calculated using the same apical and basal designations as dendritic length. Apical oblique number is the number of oblique dendrites emerging from the primary apical dendrite before tuft formation. Pia to soma is the distance from pia/L1 border to center of soma. Values are mean \pm SEM. Significant comparisons $(p<0.05)$ were determined by ANOVA followed by two-sample $t$ test with Holm-Sidak correction.

classes, quinpirole-dependent modulation was observed only in the AIS of D3+ neurons (D3+ AIS G/G $G_{\text {sat }}: 60 \pm 5 \%$ of baseline; ANOVA, D1+/D2+/D3+, $F_{(2,14)}=13.38, p=6 \times 10^{-4}$; twosample $t$ test, Holm-Sidak correction, D1+ vs D $3+: t_{(12)}=5.90$,
$\mathrm{D} 2+$ vs D3+: $\left.t_{(9)}=3.25 ; p<0.05\right)$. Consistent with these voltage-clamp results, $1 \mu \mathrm{M}$ TTA-P2 reduced spike-evoked Ca influx in current-clamp recordings from Type 3 neurons (Fig. 7C: normalized $\left.\Delta G / G_{\text {sat }}: 0.67 \pm 0.03, n=5\right)$. Quinpirole did not alter 

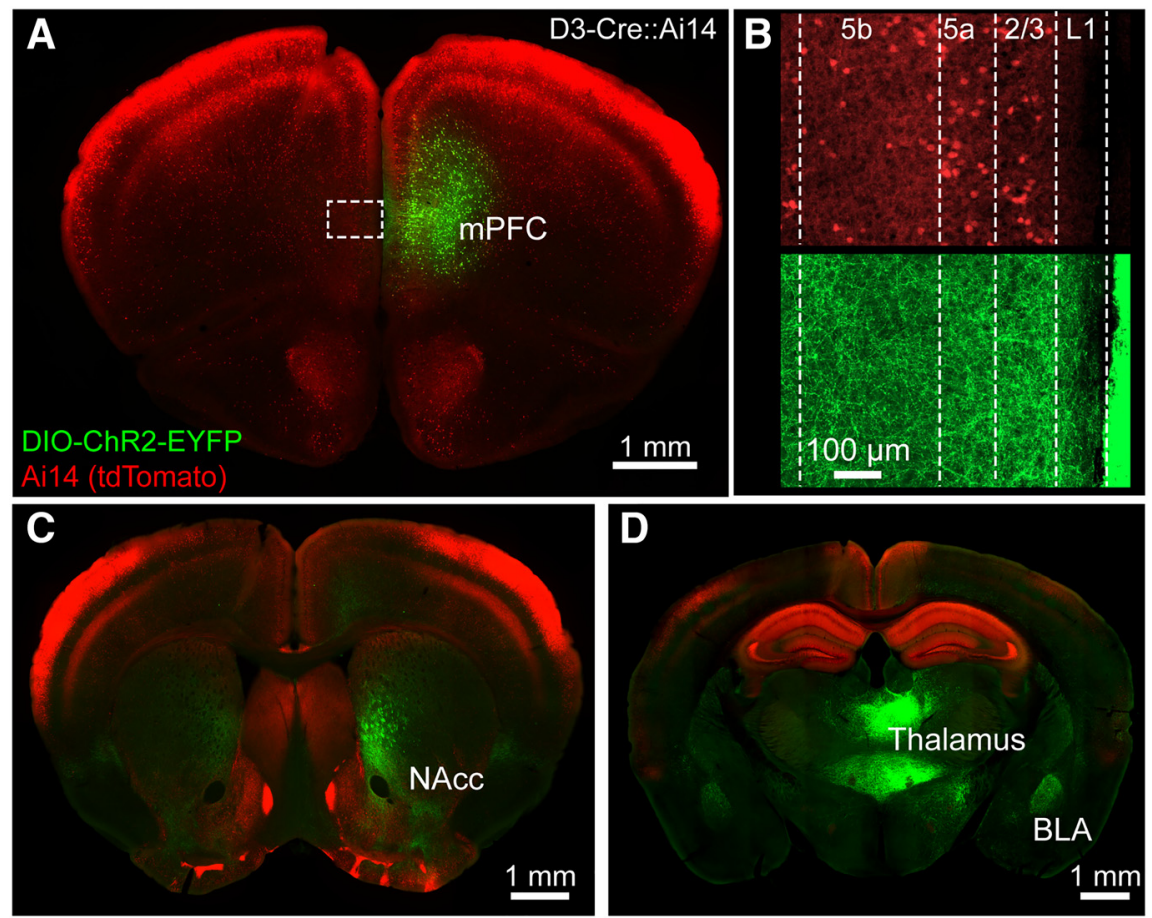

Figure 5. Prefrontal D3 + neuron projection patterns are revealed by orthograde tracing. $A$, Coronal section of D3-Cre::Ai14 mouse transfected with AAV-DI0-ChR2-EYFP in the right hemisphere (replicated in three animals). D3 + neurons throughout mPFC cortical laminae are labeled. $\boldsymbol{B}$, Confocal images (area from inset in $\boldsymbol{A}$ ) of mPFC D3 + neurons (top) and transfected axon fibers (bottom) contralateral to the injection site. $\boldsymbol{C}, \boldsymbol{D}$, Images taken from same animal as in $\boldsymbol{A}$. Axons are prominent bilaterally within ventral striatum, including NAcc, BLA, and multiple thalamic nuclei.

AIS Ca after TTA-P2 application or in $\mathrm{Ca}_{\mathrm{V}} 3.2$ knock-out mice, indicating that $\mathrm{Ca}_{\mathrm{V}} 3.2$ isoforms are the target of $\mathrm{D} 3 \mathrm{R}$ modulation (Fig. $7 B, C$ : normalized $\Delta G / G_{\text {sat }}$, quinpirole in TTA, normalized to pre-TTA baseline: $0.66 \pm 0.02, n=5$, Wilcoxon's signed-rank test vs TTA baseline: $p=0.44 ; \mathrm{Ca}_{\mathrm{V}} 3.2^{-l-}: 0.98 \pm 0.04, n=5, p<$ $0.05)$. Overall, these data indicate that, whereas AIS Ca channels are common to multiple neuron classes (Bender and Trussell, 2009; but see Yu et al., 2010), they are subject to AIS neuromodulation only in neurons that coexpress D3R and these cells can be distinguished based on electrophysiological properties.

$\mathrm{Ca}_{\mathrm{V}} 3$ channels underlie burst generation in multiple cell classes (Williams and Stuart, 1999; Cain and Snutch, 2010) and modulating AIS $\mathrm{Ca}_{\mathrm{V}} 3$ channels can suppress both evoked and spontaneous spike burst generation in cartwheel cells (Bender et al., 2010, 2012). Because bursts initiate in the AIS of pyramidal neurons (Kole, 2011), we hypothesized that AIS Ca channel modulation could suppress burst firing in D3 + cells. To test this, we first suppressed AIS Ca influx during evoked spike trains with targeted iontophoresis of the Ca channel antagonist $\mathrm{Ni}$. In these experiments, control and Ni-paired bursts were interleaved and iontophoretic intensity was calibrated to match the relative reduction in AIS Ca influx observed after dopaminergic modulation (Fig. 8A-D). This partial block of AIS $\mathrm{Ca}_{\mathrm{V}}$ channels is a good approximation of the actions of D3R because we showed recently that D3R signaling acts to hyperpolarize voltage-dependent steady-state inactivation of AIS-localized $\mathrm{Ca}_{\mathrm{V}} 3.2$ channels (Yang et al., 2016). This reduces channel availability at resting $V_{\mathrm{m}}$ and is therefore similar to antagonist block. Local Ca influx in response to a train of APs $(3 \times 50 \mathrm{~Hz})$ was reduced to $0.61 \pm 0.02$ of baseline when Ni iontophoresis was focused on the AIS $(n=8)$. AIS Ca was not altered if the pipette was targeted to a neighboring basal dendrite 15-20 $\mu \mathrm{m}$ from the AIS, suggesting that Ni iontospike rate was unchanged (Fig. $8 F$ : AIS Ni: $1.03 \pm 0.09$ of baseline, dendrite Ni: $1.03 \pm 0.04$; Wilcoxon's rank-sum test, $p=0.43$ ). Similarly, D3R-dependent modulation also reduced event output through a selective suppression of bursts and these effects were blocked by preapplication of sulpiride (events, quinpirole: $0.79 \pm 0.06$ of baseline, $n=5$; events, sulpiride + quinpirole: $1.05 \pm 0.05, n=5$, Wilcoxon's rank-sum test: $\mathrm{W}=16, p=0.016$ bursts, quinpirole: $0.14 \pm 0.09$; bursts, sulpiride + quinpirole: $1.08 \pm 0.11$, Wilcoxon's rank-sum test: $\mathrm{W}=15, p=0.008$; single spikes, quinpirole: $0.90 \pm 0.08$; single spikes, sulpiride + quinpirole: $1.02 \pm 0.09$, Wilcoxon's rank-sum test: $p=0.22$ ). This suggests that regulation of AIS Ca influx is a critical determinant for AP burst output in D3 + neurons and that D3Rs can regulate selectively the temporal features of spike output from this pyramidal cell class.

\section{Discussion}

Although the D3R has been observed previously in L5 PFC in both primate and rodent (Bouthenet et al., 1991; Lidow et al., 1998) and has a role in prefrontal-dependent behaviors (Nakajima et al., 2013), how it regulates neuronal function has been unclear. Combining electrophysiological and imaging approaches, we identified a novel class of IT neurons in which D3Rs regulated neuronal excitability at the AIS. Using a supervised machine learning approach, we found that dopamine receptor expression (D1, D2, D3) strongly predicted the subthreshold and suprathreshold electrophysiological properties of $\mathrm{mPFC}$ neurons. Dopamine receptor expression correlated with morphological differences between the subtypes, as well as differences in laminar distribution. D3 + cells were further distinguished from D2 + cells by their axonal projection targets. Although D2+, Type 2 neurons targeted subcortical regions such as the pons and thalamus, D3+ 
A
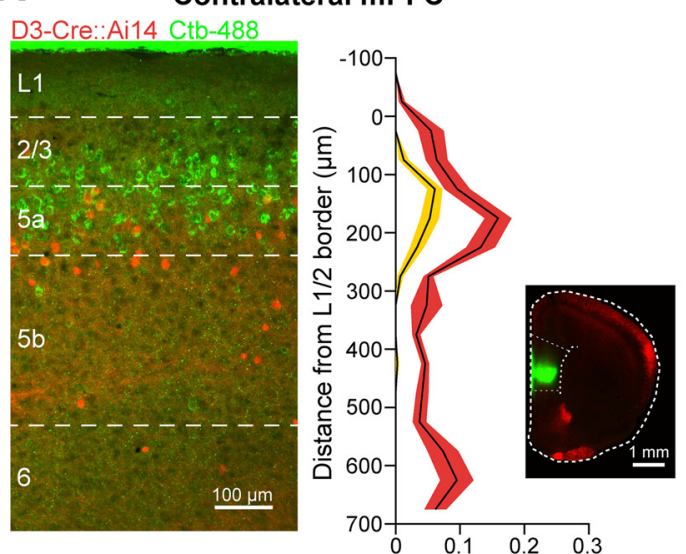

Ipsilateral BLA
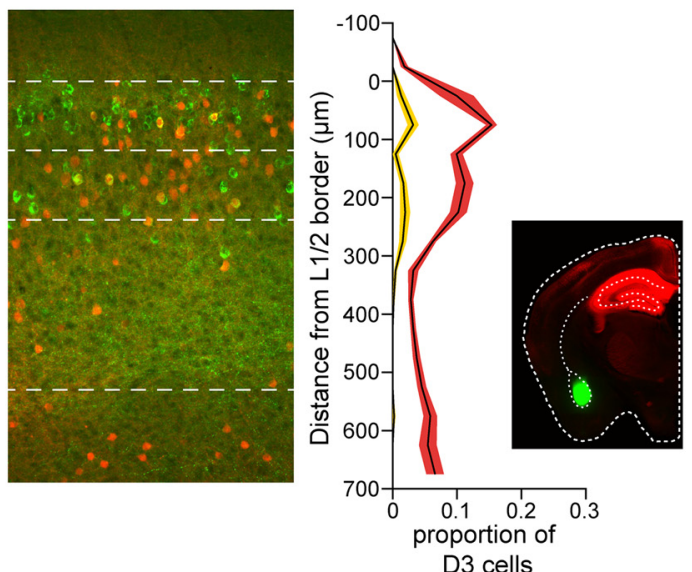

Ipsilateral NAc core
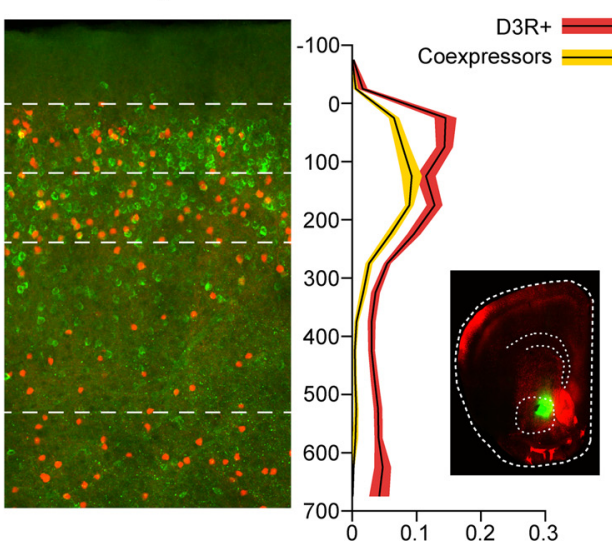

Ipsilateral MD Thalamus
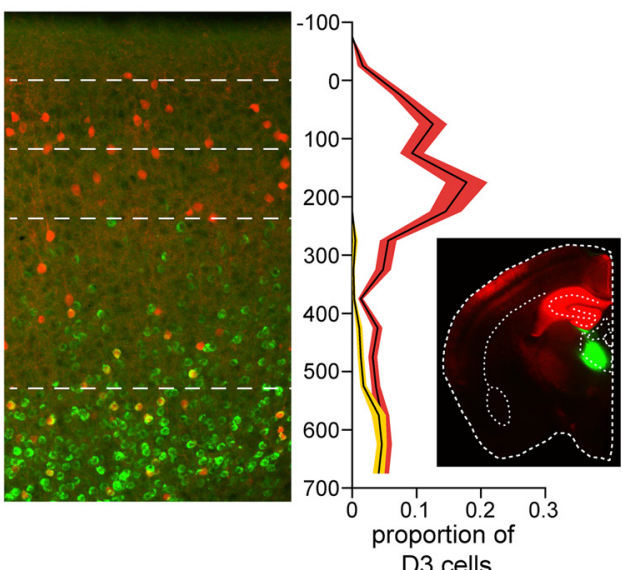

B

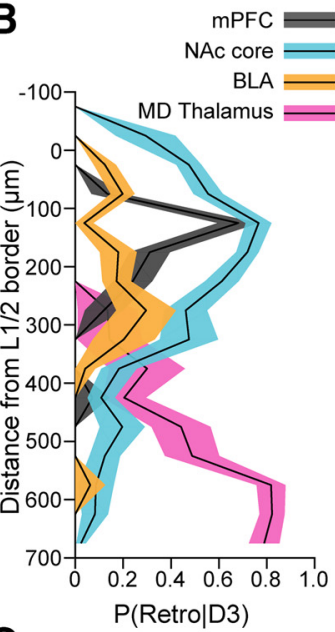

C

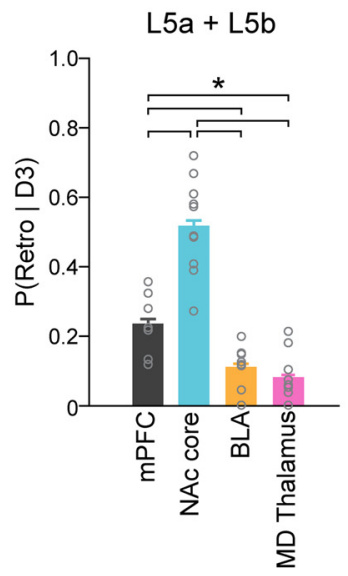

Figure 6. Retrograde tracing confirms IT targets of $L 5 \mathrm{D} 3+\mathrm{mPFC}$ neurons. $A, \mathrm{D} 3$-Cre::Ai14 adult mice were injected in four brain regions with retrograde tracer cholera toxin conjugated to green fluorophore Alexa Fluor 488. Left, Confocal images of mPFC showing D3R + and retrogradely labeled cells. Right, Distribution of both D3R + (red) and colabeled (yellow) somatic distances from L1/2 border normalized to maximum number of D3 + cells. Distributions are pooled from two to three injections per group, three to four slices/animal. Solid line with shaded region indicates mean \pm SEM. Insets, Example images of injection targeting. $\boldsymbol{B}$, Probability that a D3R + cell projected to a particular brain region plotted as a function of distance from $L 1 / 2$ border. Solid line with shaded region indicates mean \pm SEM. C, Probability as in $\boldsymbol{B}$, specifically within L5. Error bars indicate mean \pm SEM. ${ }^{*} p<0.05$, ANOVA, two-sample $t$ test (Holm-Sidak correction); $n=7 / 10 / 8 / 9$, $\mathrm{mPFC} / \mathrm{NAcc} / \mathrm{BLA} / \mathrm{MD}$.

neurons had projection patterns more consistent with $\mathrm{D} 1+$ neurons, including projections to contralateral $\mathrm{mPFC}$ and bilateral NAcc and BLA (Dembrow et al., 2010; Gee et al., 2012; Seong and Carter, 2012; Land et al., 2014). Based on these results, we propose that D1R, D2R, and D3R expression defines largely distinct L5 pyramidal cell classes in $\mathrm{MPFC}$, each with unique catecholaminergic responses.

\section{Cell-class-specific function of neuromodulatory receptors}

Although we describe three prefrontal L5 pyramidal neuron subtypes, prior studies largely focused on two subtypes: thick-tufted PT neurons with regular firing and large voltage sag and thintufted IT neurons with spike adaptation and low voltage sag (Morishima and Kawaguchi, 2006; Dembrow et al., 2010; Gee et al., 2012; Seong and Carter, 2012). D3+ neurons are likely a subset of the previously described IT neurons and were identified by characterizing multiple electrophysiological parameters. This is consistent with other recent studies reporting heterogeneity in cortically projecting, low-voltage-sag subtypes, in which both intrinsic firing patterns and response to neuromodulators help to describe two to three distinct groups (Otsuka and Kawaguchi, 2011; Avesar and Gulledge, 2012; van Aerde et al., 2015).
Although we found that D1+, D2+, and D3+ pyramidal neurons were generally distinct cell classes, we did identify a fraction of genetically labeled neurons $(\sim 14 \%)$ that had an electrophysiological phenotype not predicted by their fluorescent marker (Fig. 2F). These cross-classified cells may represent a subset of cells that coexpress dopamine receptors because colabeled cells were also observed in D1-tdTomato/D3-cre animals ( $29 \%$ of D $3+$ cells and $9 \%$ of D1 + cells). Coexpression of D1R and D2R occurs in a similar fraction of cells in areas of the ventral striatum, including the NAc core and shell (Bertran-Gonzalez et al., 2008). Although coexpressing neurons comprise a small fraction of the pyramidal cell population in $\mathrm{mPFC}$, further work will be needed to determine whether dopamine affects these neuronal populations differently than those that express a single dopamine receptor. In addition, all five dopamine receptor subtypes are expressed in L5 PFC (Lidow et al., 1998). D4 and D5 reporter lines suggest that both receptors localize to cells in L5b and L6 and colabeling studies in nonhuman primates indicate that D1 and D5 colabel pyramidal cells (Bergson et al., 1995; Gong et al., 2003; Noaín et al., 2006). How these different distributions of dopamine receptors contribute to PFC processing will be important to determine. 
A
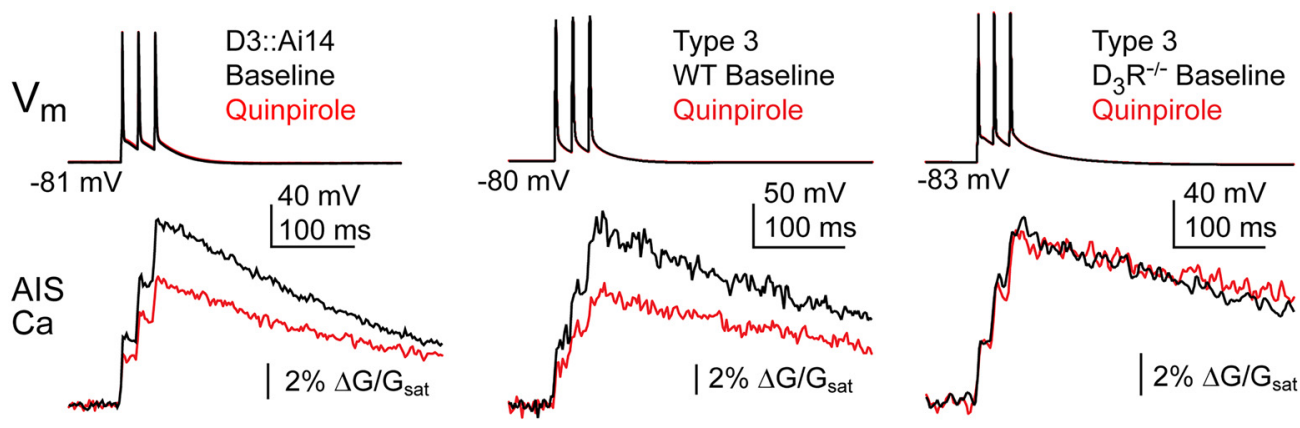

B
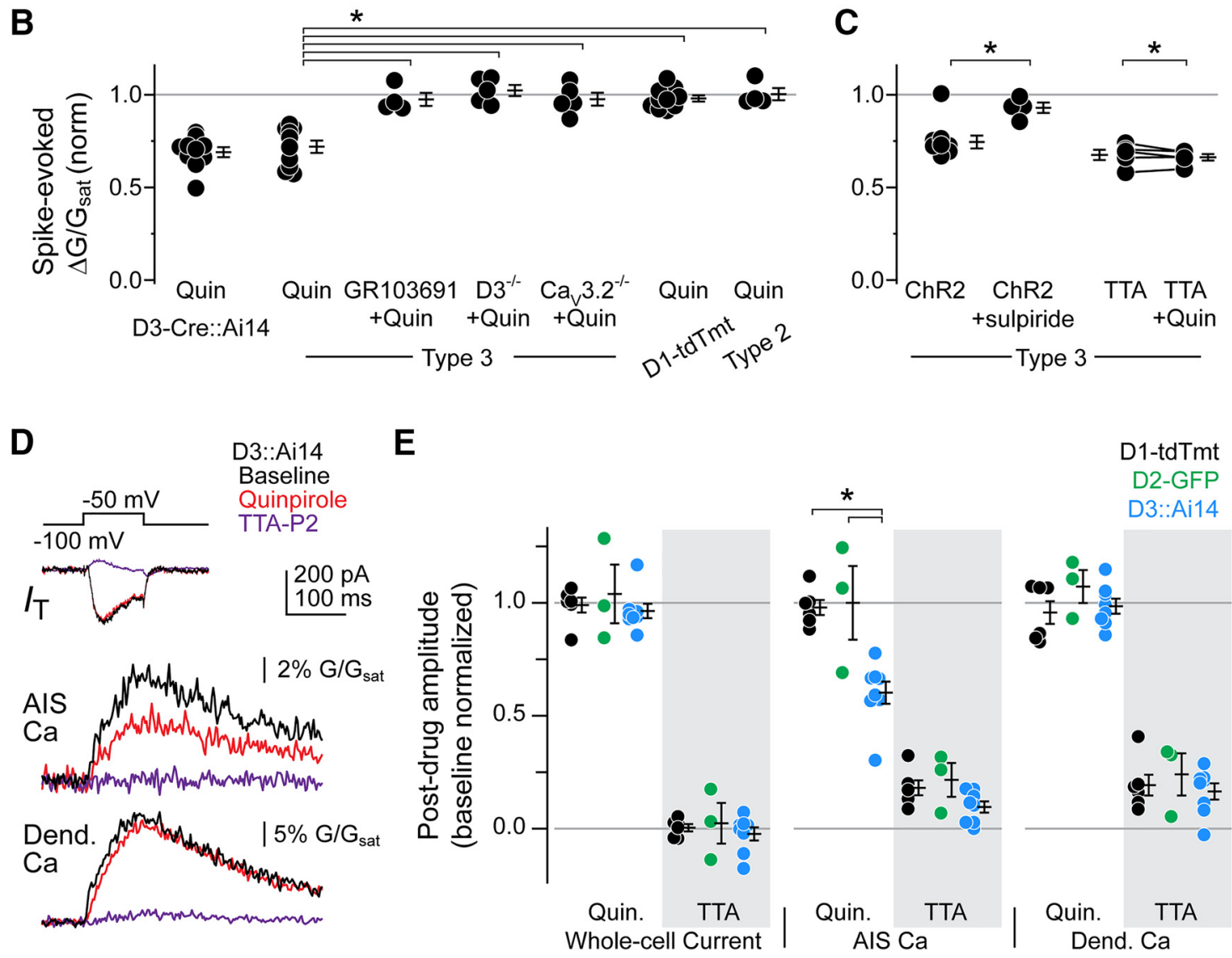

Figure 7. D3R modulation of AIS Ca is specific to a subclass of pyramidal cell. $A$, Spike-evoked ( $3 \times 50 \mathrm{~Hz}$ ) AIS Ca influx was imaged at identical time points before and after quinpirole in D3 + neurons from D3-Cre::Ai14 mice (left) and Type 3 neurons from wild-type (middle) or D3R ${ }^{-1-}$ mice (right). B, AIS Ca transient amplitude normalized to baseline. GR103691 was present during baseline imaging. Circles are single cells. Error bars indicate mean \pm SEM. ${ }^{*} p<0.05$, ANOVA, two-sample $t$ test (Holm-Sidak correction). Note: For clarity in the figure, we only indicate significant comparisons in relationship to quinpirole-treated Type 3 cells. C, Left, Optogenetic activation of endogenous catecholaminergic fibers in TH-Cre::Ai32 mice was sufficient to modulate AIS Ca. Effects were blocked by sulpiride. ${ }^{*} p<0.05$, Wilcoxon's rank-sum test. Right, In TTA experiments, lines connect cells in which quinpirole was applied after the Ca 3 channel antagonist TTA-P2. Data are normalized to pre-TTA conditions. ${ }^{*} p=0.44$, Wilcoxon's signed-rank test. Circles are single cells. Error bars indicate mean \pm SEM. $D$, Voltage step that activates $\mathrm{Ca}_{\mathrm{s}} 3$ channels in a D3 + neuron evoked both AIS and dendritic Ca influx; quinpirole Ca modulation was specific to AIS. Ca influx in both locations and whole-cell current were suppressed by TTA-P2. E, Voltage-clamp experiments performed in fluorescently identified D1 +, D2 +, and D3+ mPFC neurons, using a voltage step to activate T-type channels as in $\boldsymbol{D}$. Whole-cell current and AIS or dendrite Ca influx after quinpirole and then TTA-P2 application are plotted normalized to baseline. Circles are single cells. Error bars indicate mean \pm SEM. ${ }^{*} p<0.05$, ANOVA, two-sample $t$ test (Holm-Sidak correction).

The mPFC also receives convergent input from numerous ascending neuromodulatory pathways, including serotonergic, cholinergic, and adrenergic afferent systems. Our study adds to growing evidence that modulatory regulation of prefrontal neurons depends strongly on their long-range targets (Dembrow and Johnston, 2014). For example, pyramidal cell integration of serotonergic input is also subtype specific, with excitatory and biphasic responses to serotonin by IT neurons via 5-HT2A receptors and purely inhibitory responses by PT neurons via 5-HT1A re- ceptors (Avesar and Gulledge, 2012). This result suggests the PT D2 + subtype may coexpress the 5-HT1A receptor, whereas D1+ and/or D3+ subtypes may coexpress the 5-HT2A receptor. In addition, IT and PT mPFC neurons also undergo differential adrenergic and cholinergic modulation, with both neuromodulators having larger effects on PT cell excitability, in part through HCN channels that are expressed at higher levels in PT cells (Dembrow et al., 2010). Determining the overlap or segregation of these subcircuits within the mPFC will advance our under- 
A

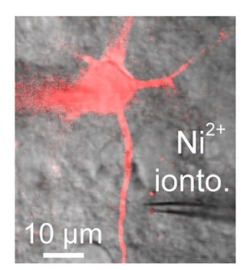

B
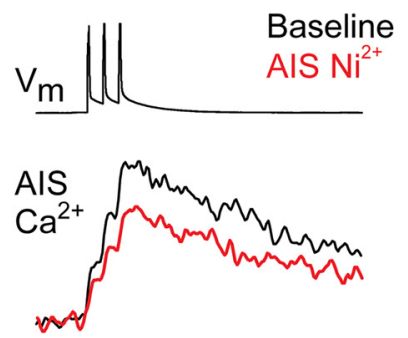

D

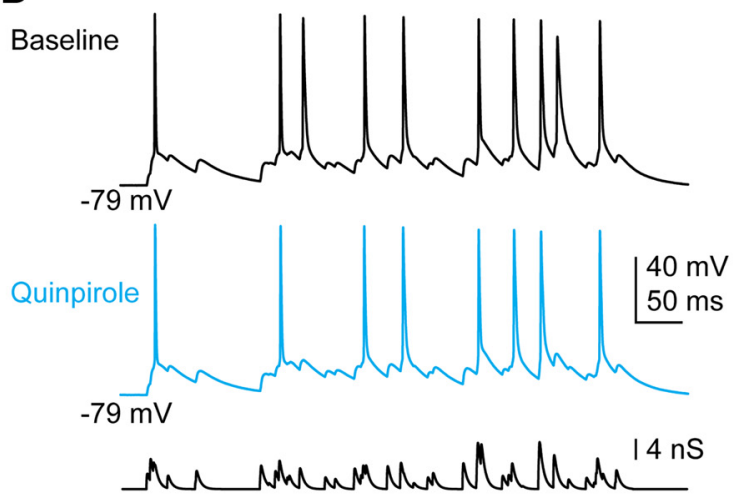

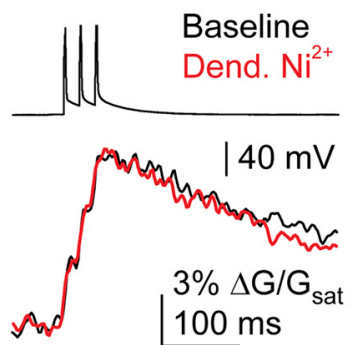

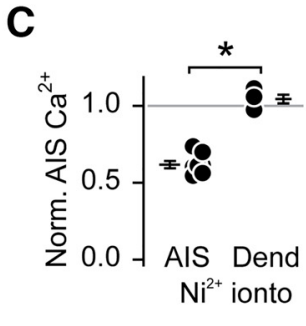

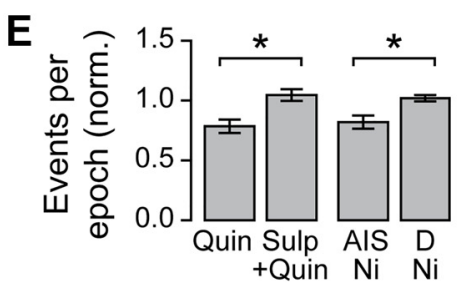
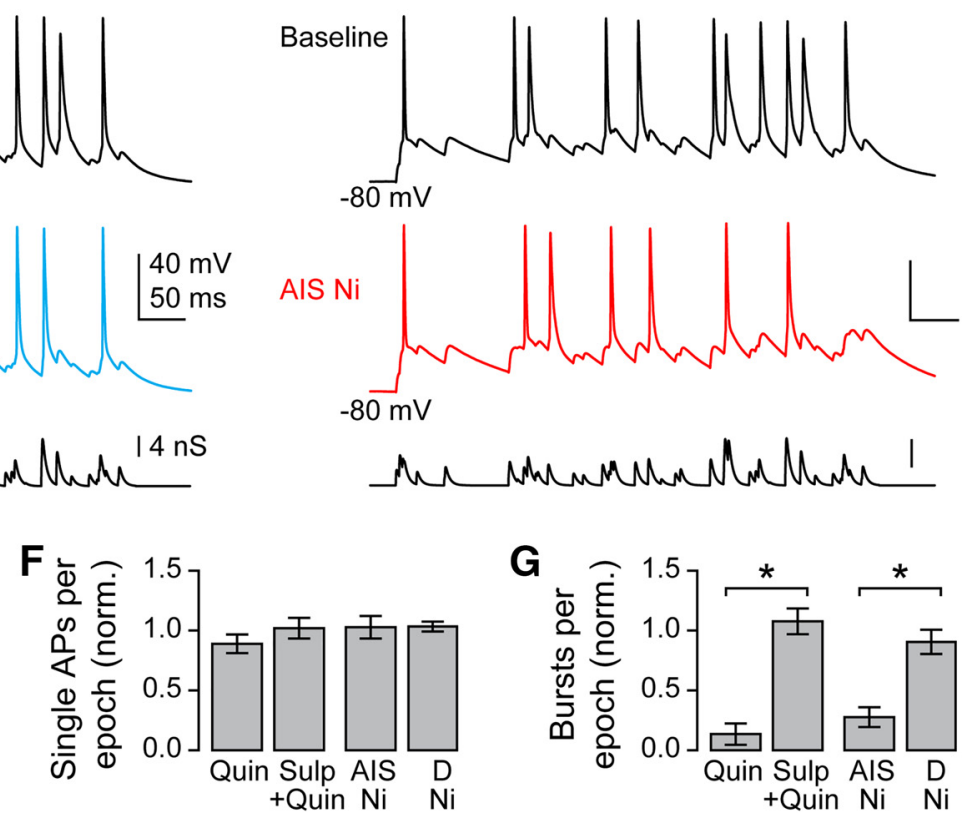

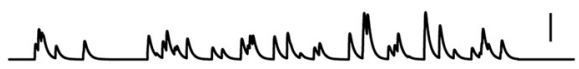

Figure 8. Modulation of AIS Ca suppresses burst initiation. $A$, Schematic of Ni iontophoresis location. $B$, AIS Ca influx was suppressed only when Ni was localized to the AIS. Traces are from a single experiment. C, AIS Ca transient amplitude normalized to interleaved controls after AIS- and dendrite-targeted Ni iontophoresis. ${ }^{*} p<0.05$, Wilcoxon's rank-sum test. $\boldsymbol{D}$, Spiking in response to a train of EPSG-like stimuli after bath quinpirole (left, cyan) or before and during AIS Ni (right, red) application. $\boldsymbol{E}-\mathbf{G}$, Spike events in baseline and drug-treated conditions normalized to baseline values in each experiment. Bursts (defined as spike frequencies $>50 \mathrm{~Hz}$ ) were reduced after AIS Ca modulation. Error bars indicate mean \pm SEM. ${ }^{*} p<0.05$, Wilcoxon's rank-sum test; $n=5 / 5 / 6 / 3$, quinpirole, sulpiride + quinpirole, AIS Ni, AIS dendrite, respectively.

standing of how concerted actions by neuromodulators affect prefrontal network activity.

\section{Implications for $\mathrm{mPFC}$ D3 receptor function in health and disease}

An analysis of mPFC pyramidal cell subclass anatomy and electrophysiology, combined with the functional analysis of D3R here and D1R/D2R in previous work (Gee et al., 2012; Seong and Carter, 2012), revealed that some cell-intrinsic aspects of dopaminergic modulation in $\mathrm{mPFC}$ are subclass dependent. Although $\mathrm{Ca}_{\mathrm{V}} 3$-mediated AIS Ca influx was present in all three cell classes (Fig. 7, but see Yu et al., 2010), channel modulation occurred only in D3R-expressing neurons, identified either through fluorescent tag (D3-Cre::Ai14) or electrophysiological identification (Type 3). Modulation was restricted to AIS-localized $\mathrm{Ca}_{\mathrm{V}} 3$ channels, consistent with previous findings in D3R-expressing auditory brainstem neurons (Bender et al., 2010, 2012; Yang et al., 2016). Within these neurons, we observed a marked reduction of both evoked and spontaneous bursts (Bender and Trussell, 2009; Bender et al., 2012). Here, we find similar effects in D3+ mPFC pyramidal cells (Fig. 8). AIS Ca channels are common to broad neuronal classes (Schiller et al., 1995; Callewaert et al., 1996; Lüscher et al., 1996; Bender and Trussell, 2009; Yu et al., 2010; François et al., 2015; Gründemann and Clark, 2015; Martinello et al., 2015; Apostolides et al., 2016) and D3Rs are broadly distrib- uted, especially in limbic regions (Bouthenet et al., 1991; Lévesque et al., 1992, also see Fig. 5). Therefore, AIS Ca modulation may be a common mechanism by which D3Rs regulate neuronal excitability throughout the brain.

In vivo, prefrontal neurons exhibit sparse AP firing, interspersed with short, high-frequency bursts (Boudewijns et al., 2013). Selective reduction of AP burst output in D3R-expressing neurons provides a novel mechanism for dopaminergic modulation to regulate $\mathrm{mPFC}$ information processing because both behavioral and physiological evidence suggests that AP bursts contain a distinct neural code. Prefrontal bursting is both modulated by and predictive of learning within multiple behavioral paradigms (Laviolette et al., 2005; Burgos-Robles et al., 2007). At the synaptic level, bursts facilitate plasticity, producing dendritic Ca-regenerative activity and depolarization required for NMDA receptor activation (Kampa et al., 2007). In addition, high-frequency bursts increase synaptic transmission reliability, especially at synapses with low release probability that exhibit short-term facilitation (Lisman, 1997). Moreover, release probability can vary based on postsynaptic target (Markram et al., 1998). If this variability exists within D3R-expressing pyramidal cell networks, then burst regulation may route information to specific postsynaptic networks in a dopamine-dependent manner.

D3Rs have long been considered a potential therapeutic target for the treatment of serious mental illness (Sokoloff and Le Foll, 
2017), especially because currently prescribed antipsychotics have high D3R affinity (Joyce and Millan, 2005). Determining a specific role for D3R in mental illness has been hampered by our poor understanding of its cellular distribution and function in prefrontal circuits. Here, we demonstrated that D3Rs have a distinct role within mPFC. Although both D2Rs and D3Rs are generally thought to signal through $\mathrm{G}_{\mathrm{i} / \mathrm{o}}$, AIS Ca was only modulated in D3R-expressing neurons, not in neighboring D2R-expressing neurons. Indeed, we showed recently that D3Rs regulate AIS $\mathrm{Ca}_{\mathrm{V}} 3.2$ channels through a noncanonical, arrestin-dependent pathway, both in auditory brainstem neurons and in heterologous expression systems (Yang et al., 2016). Interestingly, arrestin-biased compounds have been shown recently to alleviate schizophrenia-like phenotypes in mouse models (Urs et al., 2016). As targeted therapies continue to be developed, future work will be critical to determine whether interactions with MPFC D3Rs contribute to antipsychotic efficacy.

\section{References}

Apostolides PF, Milstein AD, Grienberger C, Bittner KC, Magee JC (2016) Axonal filtering allows reliable output during dendritic plateau-driven complex spiking in CA1 neurons. Neuron 89:770-783. CrossRef Medline

Avesar D, Gulledge AT (2012) Selective serotonergic excitation of callosal projection neurons. Front Neural Circuits 6:12. CrossRef Medline

Bender KJ, Trussell LO (2009) Axon initial segment Ca2 + channels influence action potential generation and timing. Neuron 61:259-271. CrossRef Medline

Bender KJ, Ford CP, Trussell LO (2010) Dopaminergic modulation of axon initial segment calcium channels regulates action potential initiation. Neuron 68:500-511. CrossRef Medline

Bender KJ, Uebele VN, Renger JJ, Trussell LO (2012) Control of firing patterns through modulation of axon initial segment T-type calcium channels. J Physiol 590:109-118. CrossRef Medline

Bergson C, Mrzljak L, Smiley JF, Pappy M, Levenson R, Goldman-Rakic PS (1995) Regional, cellular, and subcellular variations in the distribution of D1 and D5 dopamine receptors in primate brain. J Neurosci 15:78217836. Medline

Bertran-Gonzalez J, Bosch C, Maroteaux M, Matamales M, Hervé D, Valjent E, Girault JA (2008) Opposing patterns of signaling activation in dopamine D1 and D2 receptor-expressing striatal neurons in response to cocaine and haloperidol. J Neurosci 28:5671-5685. CrossRef Medline

Boudewijns ZS, Groen MR, Lodder B, McMaster MT, Kalogreades L, de Haan R, Narayanan RT, Meredith RM, Mansvelder HD, de Kock CP (2013) Layer-specific high-frequency action potential spiking in the prefrontal cortex of awake rats. Front Cell Neurosci 7:99. CrossRef Medline

Bouthenet ML, Souil E, Martres MP, Sokoloff P, Giros B, Schwartz JC (1991) Localization of dopamine D3 receptor mRNA in the rat brain using in situ hybridization histochemistry: comparison with dopamine D2 receptor mRNA. Brain Res 564:203-219. CrossRef Medline

Burgos-Robles A, Vidal-Gonzalez I, Santini E, Quirk GJ (2007) Consolidation of fear extinction requires NMDA receptor-dependent bursting in the ventromedial prefrontal cortex. Neuron 53:871-880. CrossRef Medline

Cain SM, Snutch TP (2010) Contributions of T-type calcium channel isoforms to neuronal firing. Channels (Austin) 4:475-482. CrossRef Medline

Callewaert G, Eilers J, Konnerth A (1996) Axonal calcium entry during fast "sodium" action potentials in rat cerebellar Purkinje neurones. J Physiol 495:641-647. CrossRef Medline

Dembrow N, Johnston D (2014) Subcircuit-specific neuromodulation in the prefrontal cortex. Front Neural Circuits 8:54. CrossRef Medline

Dembrow NC, Chitwood RA, Johnston D (2010) Projection-specific neuromodulation of medial prefrontal cortex neurons. J Neurosci 30:1692216937. CrossRef Medline

DeNardo LA, Berns DS, DeLoach K, Luo L (2015) Connectivity of mouse somatosensory and prefrontal cortex examined with trans-synaptic tracing. Nat Neurosci 18:1687-1697. CrossRef Medline

François A, Schüetter N, Laffray S, Sanguesa J, Pizzoccaro A, Dubel S, Mantilleri A, Nargeot J, Noël J, Wood J, Moqrich A, Pongs O, Bourinet E (2015) The low-threshold calcium channel Cav3.2 determines lowthreshold mechanoreceptor function. Cell Rep 10:370-382. CrossRef Medline
Gee S, Ellwood I, Patel T, Luongo F, Deisseroth K, Sohal VS (2012) Synaptic activity unmasks dopamine $\mathrm{D} 2$ receptor modulation of a specific class of layer V pyramidal neurons in prefrontal cortex. J Neurosci 32:49594971. CrossRef Medline

Gerfen CR, Surmeier DJ (2011) Modulation of striatal projection systems by dopamine. Annu Rev Neurosci 34:441-466. CrossRef Medline

Glickstein SB, Hof PR, Schmauss C (2002) Mice lacking dopamine D2 and D3 receptors have spatial working memory deficits. J Neurosci 22:56195629. Medline

Glickstein SB, Desteno DA, Hof PR, Schmauss C (2005) Mice lacking dopamine D2 and D3 receptors exhibit differential activation of prefrontal cortical neurons during tasks requiring attention. Cereb Cortex 15:10161024. Medline

Gong S, Zheng C, Doughty ML, Losos K, Didkovsky N, Schambra UB, Nowak NJ, Joyner A, Leblanc G, Hatten ME, Heintz N (2003) A gene expression atlas of the central nervous system based on bacterial artificial chromosomes. Nature 425:917-925. CrossRef Medline

Gross G, Wicke K, Drescher KU (2013) Dopamine $\mathrm{D}_{3}$ receptor antagonism-still a therapeutic option for the treatment of schizophrenia. Naunyn Schmiedebergs Arch Pharmacol 386:155-166. CrossRef Medline

Gründemann J, Clark BA (2015) Calcium-activated potassium channels at nodes of ranvier secure axonal spike propagation. Cell Rep 12:1715-1722. CrossRef Medline

Hooks BM, Hires SA, Zhang Y-X, Huber D, Petreanu L, Svoboda K, Shepherd GM (2011) Laminar analysis of excitatory local circuits in vibrissal motor and sensory cortical areas. PLoS Biol 9:e1000572. CrossRef Medline

Joyce JN, Millan MJ (2005) Dopamine D3 receptor antagonists as therapeutic agents. Drug Discov Today 10:917-925. CrossRef Medline

Kampa BM, Letzkus JJ, Stuart GJ (2007) Dendritic mechanisms controlling spike-timing-dependent synaptic plasticity. Trends Neurosci 30:456463. CrossRef Medline

Kole MH (2011) First node of ranvier facilitates high-frequency burst encoding. Neuron 71:671-682. CrossRef Medline

Land BB, Narayanan NS, Liu RJ, Gianessi CA, Brayton CE, Grimaldi DM, Sarhan M, Guarnieri DJ, Deisseroth K, Aghajanian GK, DiLeone RJ (2014) Medial prefrontal D1 dopamine neurons control food intake. Nat Neurosci 17:248-253. CrossRef Medline

Laruelle M (2014) Schizophrenia: From dopaminergic to glutamatergic interventions. Curr Opin Pharmacol 14:97-102. CrossRef Medline

Laviolette SR, Lipski WJ, Grace AA (2005) A subpopulation of neurons in the medial prefrontal cortex encodes emotional learning with burst and frequency codes through a dopamine D4 receptor-dependent basolateral amygdala input. J Neurosci 25:6066-6075. CrossRef Medline

Lévesque D, Diaz J, Pilon C, Martres MP, Giros B, Souil E, Schott D, Morgat JL, Schwartz JC, Sokoloff P (1992) Identification, characterization, and localization of the dopamine D3 receptor in rat brain using 7- $(3 \mathrm{H})$ hydroxy- $\mathrm{N}$, N-di-n-propyl-2-aminotetralin. Proc Natl Acad Sci U S A 89:8155-8159. CrossRef Medline

Lidow MS, Wang F, Cao Y, Goldman-Rakic PS (1998) Layer V neurons bear the majority of mRNAs encoding the five distinct dopamine receptor subtypes in the primate prefrontal cortex. Synapse 28:10-20. CrossRef Medline

Lisman JE (1997) Bursts as a unit of neural information: making unreliable synapses reliable. Trends Neurosci 20:38-43. CrossRef Medline

Lüscher C, Lipp P, Lüscher HR, Niggli E (1996) Control of action potential propagation by intracellular $\mathrm{Ca} 2+$ in cultured rat dorsal root ganglion cells. J Physiol 490:319-324. CrossRef Medline

Markram H, Wang Y, Tsodyks M (1998) Differential signaling via the same axon of neocortical pyramidal neurons. Proc Natl Acad Sci U S A 95: 5323-5328. CrossRef Medline

Martinello K, Huang Z, Lujan R, Tran B, Watanabe M, Cooper EC, Brown DA, Shah MM (2015) Cholinergic afferent stimulation induces axonal function plasticity in adult hippocampal granule cells. Neuron 85:346363. CrossRef Medline

McCormick DA, Prince DA (1987) Post-natal development of electrophysiological properties of rat cerebral cortical pyramidal neurones. J Physiol 393:743-762. CrossRef Medline

McCormick DA, Shu Y, Yu Y (2007) Neurophysiology: Hodgkin and Huxley model- still standing? Nature 445:E1-E2; discussion E2-E3. CrossRef Medline

Millan MJ, Buccafusco JJ, Loiseau F, Watson DJ, Decamp E, Fone KC, Thomasson-Perret N, Hill M, Mocaer E, Schneider JS (2010) The dopa- 
mine $\mathrm{D}$ (3) receptor antagonist, $\mathrm{S33138}$, counters cognitive impairment in a range of rodent and primate procedures. Int J Neuropsychopharmacol 13:1035-1051. CrossRef Medline

Minzer K, Lee O, Hong JJ, Singer HS (2004) Increased prefrontal D2 protein in Tourette syndrome: A postmortem analysis of frontal cortex and striatum. J Neurol Sci 219:55-61. CrossRef Medline

Molnár Z, Cheung AF (2006) Towards the classification of subpopulations of layer V pyramidal projection neurons. Neurosci Res 55:105-115. CrossRef Medline

Morishima M, Kawaguchi Y (2006) Recurrent connection patterns of corticostriatal pyramidal cells in frontal cortex. J Neurosci 26:4394-4405. CrossRef Medline

Nakajima S, Gerretsen P, Takeuchi H, Caravaggio F, Chow T, Le Foll B, Mulsant B, Pollock B, Graff-Guerrero A (2013) The potential role of dopamine D3 receptor neurotransmission in cognition. Eur Neuropsychopharmacol 23:799-813. CrossRef Medline

Noaín D, Avale ME, Wedemeyer C, Calvo D, Peper M, Rubinstein M (2006) Identification of brain neurons expressing the dopamine D4 receptor gene using BAC transgenic mice. Eur J Neurosci 24:2429-2438. CrossRef Medline

Otsuka T, Kawaguchi Y (2011) Cell diversity and connection specificity between callosal projection neurons in the frontal cortex. J Neurosci 31: 3862-3870. CrossRef Medline

Schiller J, Helmchen F, Sakmann B (1995) Spatial profile of dendritic calcium transients evoked by action potentials in rat neocortical pyramidal neurones. J Physiol 487:583-600. CrossRef Medline

Seong HJ, Carter AG (2012) D1 receptor modulation of action potential firing in a subpopulation of layer 5 pyramidal neurons in the prefrontal cortex. J Neurosci 32:10516-10521. CrossRef Medline

Shepherd GM (2013) Corticostriatal connectivity and its role in disease. Nat Rev Neurosci 14:278-291. CrossRef Medline

Sokoloff P, Le Foll B (2017) The dopamine D3 receptor, a quarter century later. Eur J Neurosci 45:2-19. CrossRef Medline

Urs NM, Gee SM, Pack TF, McCorvy JD, Evron T, Snyder JC, Yang X, Rodriguiz RM, Borrelli E, Wetsel WC, Jin J, Roth BL, O'Donnell P, Caron MG (2016) Distinct cortical and striatal actions of a $\beta$-arrestin-biased dopamine D2 receptor ligand reveal unique antipsychotic-like properties. Proc Natl Acad Sci U S A 113:E8178-E8186. Medline

van Aerde KI, Qi G, Feldmeyer D (2015) Cell type-specific effects of adenosine on cortical neurons. Cereb Cortex 25:772-787. CrossRef Medline

Williams SR, Stuart GJ (1999) Mechanisms and consequences of action potential burst firing in rat neocortical pyramidal neurons. J Physiol 521: 467-482. CrossRef Medline

Yang S, Ben-Shalom R, Ahn M, Liptak AT, van Rijn RM, Whistler JL, Bender KJ (2016) $\beta$-arrestin-dependent dopaminergic regulation of calcium channel activity in the axon initial segment. Cell Rep 16:1518-1526. CrossRef Medline

Yu Y, Maureira C, Liu X, McCormick D (2010) P/Q and N channels control baseline and spike-triggered calcium levels in neocortical axons and synaptic boutons. J Neurosci 30:11858-11869. CrossRef Medline

Zhang ZW (2004) Maturation of layer V pyramidal neurons in the rat prefrontal cortex: intrinsic properties and synaptic function. J Neurophysiol 91:1171-1182. Medline 